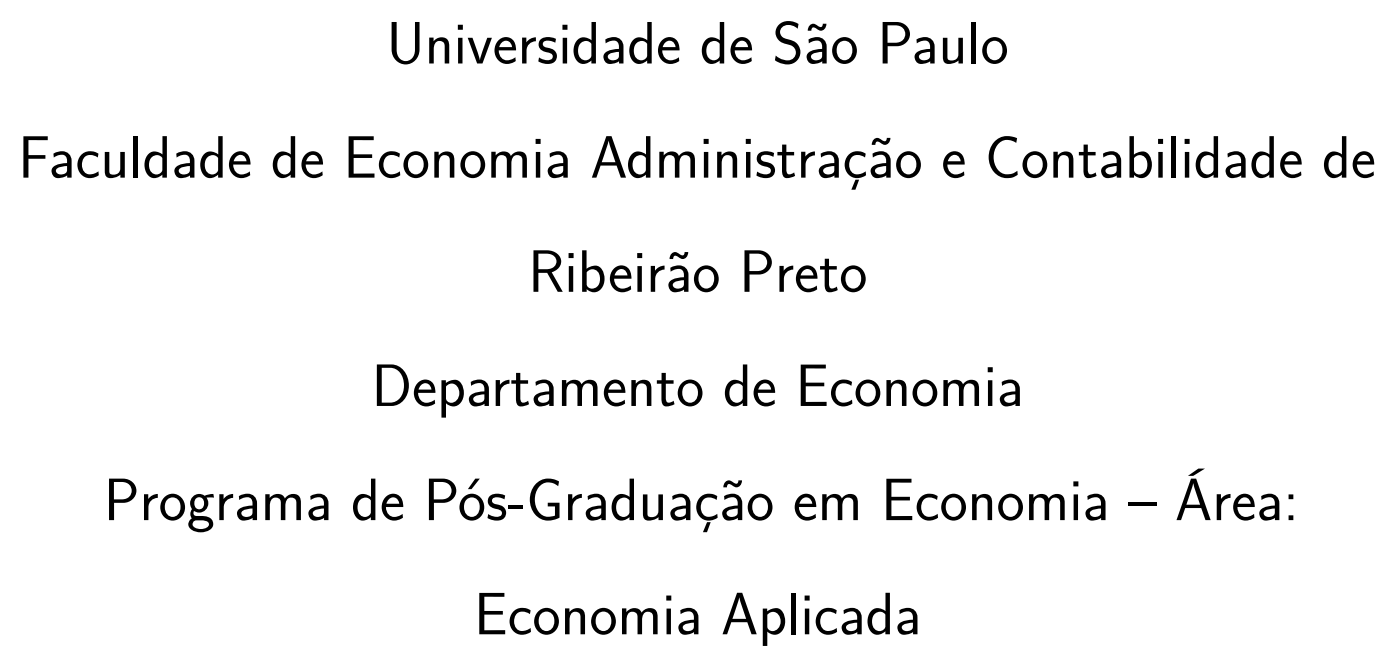

Matheus Mascioli Berlingeri

\title{
Competências socioemocionais e mercado de trabalho: um estudo para o caso brasileiro
}

Orientador: Prof. Dr. Daniel Domingues dos Santos

Ribeirão Preto 
Prof. Dr. Vahan Agopyan

Reitor da Universidade de São Paulo

Prof. Dr. Dante Pinheiro Martinelli

Diretor da Faculdade de Economia, Administração e Contabilidade de Ribeirão Preto

Prof. Dr. Sérgio Kannebley Junior

Chefe do Departamento de Economia

Prof. Dr. Sergio Naruhiko Sakurai

Coordenador do Programa de Pós-graduação em Economia - PPGE Área: Economia Aplicada 
Matheus Mascioli Berlingeri

\title{
Competências socioemocionais e mercado de trabalho: um estudo para o caso brasileiro
}

Dissertação de Mestrado apresentada ao Programa de Pós-Graduação em Economia Ârea: Economia Aplicada da Faculdade de Economia , Administração e Contabilidade de Ribeirão Preto da Universidade de São Paulo, como parte dos requisitos necessários para a obtenção do título de Mestre em Ciências. Versão Corrigida. A original encontra-se disponível na FEA-RP/USP.

Orientador: Prof. Dr. Daniel Domingues dos Santos

\author{
Ribeirão Preto
}

2018 
Autorizo a reprodução e divulgação total ou parcial deste trabalho, por qualquer meio convencional ou eletrônico, para fins de estudo e pesquisa, desde que citada a fonte.

Matheus Mascioli Berlingeri

Competências socioemocionais e mercado de trabalho: um estudo para o caso brasileiro/ Matheus Mascioli Berlingeri. Ribeirão Preto, 2018

58 p.: il.; $30 \mathrm{~cm}$.

Orientador: Prof. Dr. Daniel Domingues dos Santos

Dissertação de mestrado apresentada ao programa de Pós-Graduação em Economia - Área: Economia Aplicada da Faculdade de Economia , Administração e Contabilidade de Ribeirão Preto da Universidade de São Paulo, para a obtenção do título de Mestre em Ciências.

1. Mercado de Trabalho. 2. Competências Socioemocionais. 2. Soft Skills. I. Orientador. II. Universidade xxx. III. Faculdade de xxx. IV. Título 
Matheus Mascioli Berlingeri

\title{
Competências socioemocionais e mercado de trabalho: um estudo para o caso brasileiro
}

Dissertação de Mestrado apresentada ao Programa de Pós-Graduação em Economia Ârea: Economia Aplicada da Faculdade de Economia , Administração e Contabilidade de Ribeirão Preto da Universidade de São Paulo, como parte dos requisitos necessários para a obtenção do título de Mestre em Ciências. Versão Corrigida. A original encontra-se disponível na FEA-RP/USP.

Aprovada em

Banca Examinadora

\author{
Prof. Dr. Daniel Domingues dos \\ Santos \\ Orientador - FEA-RP/USP
}
Prof. Dr. Luiz Guilherme Dácar da Silva Scorzafave FEA-RP/USP

Prof. Dr. Ricardo Primi

USF

\section{Prof. Dr. André Portela} FGV/EESP

Ribeirão Preto

2018 


\section{Agradecimentos}

A conclusão do mestrado, celebrada com a materialização dessa dissertação, marcou o encerramento de uma fase muito significativa na minha vida. Foi uma fase que começou boa, se mostrou muito ruim logo em seguida e depois foi tomando um rumo inesperado e intenso. Foram muitas experiências vividas em pouco tempo, mas que me prepararam para o novo caminho que estou vivendo hoje.

Quando fiz o discurso da minha turma de graduação, citei uma frase do Rock Balboa que dizia: "Não importa o quanto você bate, mas o quanto a gente aguenta apanhar e continuar. O quanto pode suportar e seguir em frente. É assim que se ganha.". Meu orientador e amigo Daniel Domingues dos Santos, cuja parceria vem desde a graduação, foi meu grande técnico. Exigiu, aconselhou, ensinou e foi presente em minhas quedas e vitórias. À ele dedico esse título.

Foi o Laboratório de Estudos e Pesquisas em Economia Social (LEPES) ${ }^{1}$ do campus da Universidade de São Paulo (USP) de Ribeirão Preto meu espaço de treinamento. Aos professores Luiz Guilherme e Elaine Pazallo, agradeço por tanto contribuírem para minha formação. Aos amigos do LEPES, Batata, Beth, Chapéu, Lobão, Sunga, Paul, Miró, Frank, Nó, Duda, Cali, Erica, Vanessa, Bruna, Luna, Cigano, Denis, Legume, Nelson, Reis, Lima e Anazawa... indescritíveis.

Aos queridos amigos da minha turma de mestrado, dedico a vocês um brinde de Sub Zero acompanhado de um delicioso X-Costela, sentado na esquina do Marcão ao som de Conselho - Grupo Revelação.

Aos queridos amigos da pós-graduação, departamento de economia, demais professores e funcionários, obrigado por sempre me tratarem com atenção e carinho durante o tempo que estive em Ribeirão.

Por fim, quero agradecer à minha família por todo apoio incondicional e suporte durante toda essa fase.

$1 \quad<$ http://lepes.fearp.usp.br/> 
"Genius is one percent inspiration, ninety-nine percent perspiration"

(EDISON, 1932) 
BERLINGERI, M. M. Competências socioemocionais e mercado de trabalho: um estudo para o caso brasileiro. 2018. 58p. Dissertação (Mestrado) - Faculdade de Economia, Administração e Contabilidade de Ribeirão Preto, Universidade de São Paulo, Ribeirão Preto, 2018.

\section{Resumo}

Rápidos avanços da tecnologia e desenvolvimentos em diversos campos da ciência têm provocado mudanças profundas no mercado de trabalho. Nesse contexto, é bem documentado o papel relevante das competências socioemocionais no desenvolvimento de competências para o trabalho, sugerindo que os retornos do mercado de trabalho para habilidades não cognitivas têm aumentado ao longo do tempo e que os retornos são particularmente fortes para indivíduos que possuem habilidades cognitivas e não cognitivas. Nosso estudo busca trazer evidências do retorno associado às competências socioemocionais no mercado de trabalho brasileiro. Encontramos evidências de que existe um retorno positivo associado às competências socioemocionais e que esse retorno é diferente entre grupos de ocupação. Acreditamos que este conhecimento possa incentivar e reforçar as parcerias entre governos, educadores, formadores, trabalhadores e empregadores, a fim de gerir melhor o impacto transformador da Quarta Revolução Industrial no emprego, nas competências e na educação do Brasil.

Palavras-chave: Mercado de Trabalho. Competências Socioemocionais. Soft Skills. 
BERLINGERI, M. M. Socio-emotional competences and labor market: a study for the Brazilian case. 2018. 58p. Dissertation (Master) - School of Economics, Business and Accounting of Ribeirão Preto, University of São Paulo, Ribeirão Preto, 2018.

\section{Abstract}

Rapid advances in technology and developments in various science fields are driving deeply changes in the labor market. In this context, the relevant role of social-emotional skills in the development of job skills is well documented, suggesting that labor market returns to non-cognitive skills have been increasing over time and the pay-offs are particularly strong for individuals who have both cognitive and non-cognitive skills. Our study seeks to bring evidence of the return associated with social-emotional skills in the Brazilian labor market. We found evidence that there is a positive return associated with socialemotional skills and that this return is different between occupation groups. We believe that this knowledge can encourage and strengthen partnerships between governments, educators, trainers, workers and employers in order to better manage the transformative impact of the Fourth Industrial Revolution on employment, skills and education in Brazil.

Keywords: Labor Market. Social-emotional Skills. Soft Skills. 


\section{Lista de ilustrações}

Figura 1 - Proficiencia em Alfabetismo por Grupo de Ocupação . . . . . . . . . . 50

Figura 2 - Score Socioemocional por Grupo de Ocupação (Inaf 2015) - Autogestão 52

Figura 3 - Score Socioemocional por Grupo de Ocupação (Inaf 2015) - Abertura ao Novo . . . . . . . . . . . . . . . . . . . . . 53

Figura 4 - Score Socioemocional por Grupo de Ocupação (Inaf 2015) - Autoconceito 54

Figura 5 - Score Socioemocional por Grupo de Ocupação (Inaf 2015) - Média SEMS 55

Figura 6 - Percentil socioemocional por decil salarial (Inaf 2015) . . . . . . . . 56

Figura 7 - Percentil socioemocional por decil salarial (Inaf 2015) - Autogestão . . 56

Figura 8 - Percentil socioemocional por decil salarial (Inaf 2015) - Abertura ao Novo 57

Figura 9 - Percentil socioemocional por decil salarial (Inaf 2015) - Autoconceito . 57

Figura 10 - Percentil socioemocional por decil salarial (Inaf 2015) - Média SEMS . 58 


\section{Lista de tabelas}

Tabela 1 - Mudanças nos diferenciais de educação/habilidades profissionais em países selecionados . . . . . . . . . . . . . . . . 14

Tabela 2 - Panorama das Competências para o Século XXI segundo Iniciativas Globais . . . . . . . . . . . . . . . . . 19

Tabela 3 - As habilidades mais citadas na Classificação Brasileira de Ocupações . 25

Tabela 4 - As três competências socioemocionais avaliadas no INAF . . . . . . . . 29

Tabela 5 - Ocupação principal atual - INAF $2015 \ldots$. . . . . . . . . . . . . . . . . . . . . . .

Tabela 6 - Distribuição dos grupos de ocupação - INAF 2015 . . . . . . . . . . . 31

Tabela 7 - Distribuição da amostra por regiões brasileiras . . . . . . . . . . . . 31

Tabela 8 - Estatísticas salariais por Grupo de Ocupação (em R\$) . . . . . . . 36

Tabela 9 - Resultados dos modelos de salários . . . . . . . . . . . . 38

Tabela 10 - Resultados do modelo de salários - grupos de ocupação . . . . . . . . . 40 


\section{Sumário}

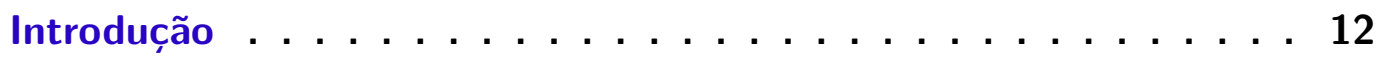

I REFERENCIAIS TEÓRICOS 17

1 A QUARTA REVOLUÇÃO INDUSTRIAL E A ESCASSEZ DE TA-

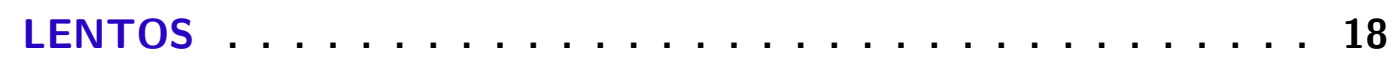

2 A CRESCENTE IMPORTÂNCIA DAS COMPETÊNCIAS SOCIOEMOCIONAIS NO MERCADO DE TRABALHO . . . . . . . 21 EVIDÊNCIAS PARA O CASO BRASILEIRO . . . . . . . 23

II ESTRATÉGIA EMPÍRICA 26

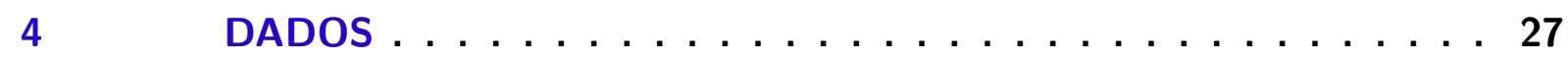

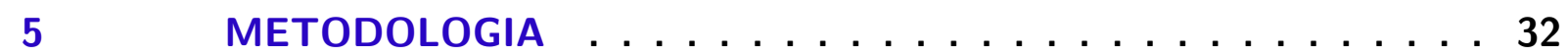

$\begin{array}{lll}\text { III RESULTADOS } & 35\end{array}$

$6 \quad$ RESULTADOS $\ldots \ldots \ldots \ldots \ldots \ldots \ldots \ldots \ldots \ldots \ldots \ldots \ldots$

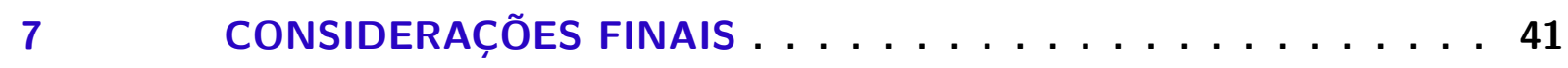

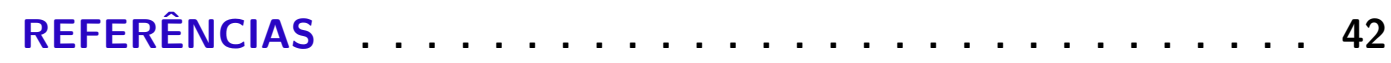

APÊNDICES $\quad 49$

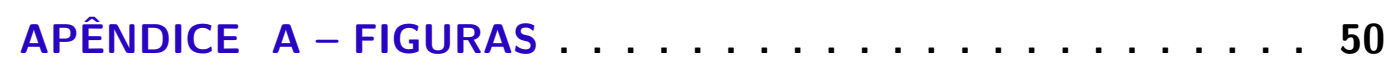




\section{Introdução}

A preocupação em entender os determinantes dos salários é um fascínio antigo que precede a própria profissão dos economistas. Estudar o que faz com que um indivíduo receba maior "recompensa" que outro no mercado de trabalho, bem como as transformações no mundo do trabalho ajudam não só a compreender as desigualdades decorrentes da natureza das próprias atividades desempenhadas, como também diversos problemas sociais como pobreza, criminalidade e outras relações de bem-estar social numa sociedade ou entre sociedades.

Adam Smith no capítulo 10 do primeiro volume do seu livro, A Riqueza das Nações, fornece uma análise compreensiva e elegante dos determinantes das diferenças salariais entre indivíduos e ocupações. Smith enfatizava que as diferenças salariais eram determinadas por fatores competitivos (diferenças nos custos de treinamento, probabilidade de sucesso, estabilidade do trabalho e outras facilidades do local de trabalho), diferenças nas habilidades inatas individuais (que ele sentiu ser relativamente sem importância) e fatores institucionais (não-competitivos) vindos do que ele chama de "leis da Europa" que regulavam salários, restringiam a mobilidade dos trabalhadores e facilitava a criação de barreiras de entrada.

Na primeira metade do século XX, estudos quantitativos da estrutura dos salários examinaram diferenças e mudanças nos salários por ocupação e na indústria (DOUGLAS et al., 1930; OBER, 1948; SLICHTER, 1950). Douglas et al. (1930), um pioneiro nos estudos empíricos da estrutura salarial, pesquisou a evolução do salário dos chamados trabalhadores white-collar e blue-collar ${ }^{2}$ nos Estados Unidos de 1890 a 1926. O autor documentou o declínio substancial do prêmio salarial para o trabalho white-collar no período (concentrado na Primeira Guerra Mundial) e argumentou que a rápida expansão do acesso à educação secundária pública levara ao crescimento da oferta de trabalhadores qualificados que superou o crescimento da demanda.

A revolução do capital humano das décadas de 1960 e 1970 e o aumento da disponibilidade de grandes bases de dados com informações de ganhos e características individuais

2 Em muitos países (como Canadá, Austrália, Reino Unido, Nova Zelândia, Dinamarca ou Estados Unidos), os grupos de indivíduos que trabalham são tipicamente classificados com base nas cores dos colarinho usados no trabalho. Trabalhadores white-collar são assim chamados por causa das camisas de colarinho branco que estavam na moda entre os trabalhadores de escritório no início e meio do século XX. Tipicamente, são pessoas que exercem trabalhos profissionais, gerenciais ou administrativos. Os trabalhadores de colarinho azul (blue-collar) por sua vez, são membros da classe trabalhadora que realizam trabalhos manuais e ganham um salário por hora ou paga uma taxa por peça pela quantidade de trabalho realizado. Eram referidos como tais, porque no início do século XX, eles geralmente usavam roupas resistentes e baratas que não mostravam sujeira facilmente, como camisas de denim ou cambricas azuis. 
alteraram a ênfase para diferenças salariais explicadas por educação e idade (ou experiência potencial no mercado de trabalho). Modelos de capital humano decorrentes da educação e investimentos em treinamento (BECKER, 1962; BECKER, 1994; BEN-PORATH, 1967; MINCER, 1974) proporcionaram uma explicação coerente de características qualitativas relativamente intemporais da estrutura salarial que foram encontradas em quase todos os países e conjunto de dados examinado (WILLIS, 1986): maiores ganhos para trabalhadores mais educados e retornos crescentes e côncavos para maiores anos de experiência no mercado. Entretanto, as dimensões quantitativas da estrutura do salário diferem substancialmente através do tempo, assim como entre países e regiões. Nesse período, Tinbergen $(1974,1975)$ chegou a especular que a evolução da tecnologia tende a ampliar a demanda por trabalhos mais qualificados e caracterizou a evolução da estrutura dos salários como uma "corrida entre o desenvolvimento tecnológico e o acesso à educação".

Nos anos 80, a pesquisa sobre mudanças na estrutura salarial e desigualdade de ganhos para os Estados Unidos e outros países da OCDE literalmente explodiu. As estruturas salariais de algumas nações da OCDE mudaram consideravelmente e os microdados de grande escala razoavelmente consistentes e comparáveis tornaram-se cada vez mais disponíveis para estudar cuidadosamente essas questões. De acordo com Katz e Autor (1999), as desigualdades salariais por educação e ocupação (especialmente relativa aos graduados no ensino superior) reduziram substancialmente em quase todas as nações avançadas durante a década de 1970. Entretanto, desde então os padrões divergentes na começaram se desenvolver.

Surgiu então na década de 90 uma vasta literatura buscando explicar as mudanças na estrutura salarial de diversos países desenvolvidos ${ }^{3}$. A Tabela 1, retirada de Katz e Autor (1999), resume as mudanças observadas na desigualdade salarial por educação e/ou ocupação de países selecionados da OCDE nas décadas de 1970 e 1980. Nota-se que a tendência para a redução dos diferenciais salariais parou ou se inverteu fortemente em meados da década de 1980 em todos esses países (exceto a Coréia do Sul). Esses padrões são sugestivos de um importante papel das diferenças nos fatores de oferta e demanda de mão-de-obra. A constatação de um declínio nos salários relativos dos menos qualificados, um aumento acentuado do desemprego desses trabalhadores, ou ambos em quase todos os países da OCDE nessas duas décadas, apesar de expandir o fornecimento relativo de trabalhadores altamente qualificados é fortemente indicativo de uma mudança comum na demanda de mão-de-obra contra os menos qualificados (KATZ et al., 1994; WOOD, 1994; NICKELL; BELL, 1995).

A partir da década de 1990, o advento dos computadores e o desenvolvimento exponencial da tecnologia no mercado de trabalho substituindo a mão-de-obra em tarefas

3 Veja, por exemplo, Bekman, Bound e Machin (1998), Davis (1992), Freeman e Katz (1994, 1995), Gottschalk e Smeeding (1997), Haskel e Slaughter (1998) e OECD (1993, 1996, 1997). 
Tabela 1 - Mudanças nos diferenciais de educação/habilidades profissionais em países selecionados

\begin{tabular}{lll}
\hline Países que experimentaram: & Década de 1970 & Década de 1980 \\
\hline & Austrália & Coréia do Sul \\
& Canadá & \\
& França & \\
Alemanha & \\
Grande queda de diferenciais & Japão & \\
& Holanda \\
& Suécia \\
& Coréia do Sul \\
& Reino Unido \\
& EUA
\end{tabular}

\section{Mudanças modestas nos diferenciais}

Queda modesta nos diferenciais

Nenhuma alteração notável nos diferenciais

Holanda

França

Alemanha

Itália

Aumento modesto de diferenciais

Austrália

Canadá

Japão

Suécia

Um grande aumento de diferenciais

Reino Unido

EUA

Fonte: retirada de Katz e Autor (1999)

de rotina de habilidade média e complementado a mão-de-obra altamente qualificada (routine-biased technological change - RBTC) propiciou um fenômeno transformador no mercado de trabalho referido como polarização do trabalho, no qual a participação no emprego nas ocupações no meio da distribuição de habilidades diminuiu rapidamente nos EUA e na Europa, ao mesmo tempo que a participação no emprego nos extremos superior e inferior da distribuição de habilidades ocupacionais aumentou substancialmente (AUTOR; LEVY; MURNANE, 2003; AUTOR; KATZ; KEARNEY, 2006; GOOS; MANNING, 2007; AUTOR; KATZ; KEARNEY, 2008; ACEMOGLU; AUTOR, 2011; AUTOR; DORN, 2013; MICHAELS; NATRAJ; REENEN, 2014; GOOS; MANNING; SALOMONS, 2014; DEMING, 2015; ADERMON; GUSTAVSSON, 2015).

Além disso, uma vasta literatura em economia tem demonstrado que aumentos nos retornos de habilidades nas últimas décadas advém da complementaridade entre tecnologia e mão de obra altamente qualificada, ou skill-biased technological change SBTC (BOUND; JOHNSON, 1989; KATZ; MURPHY, 1992; JUHN; MURPHY; PIERCE, 
1993; MURNANE; WILLETT; LEVY, 1995; GROGGER; EIDE, 1995; HECKMAN; VYTLACIL, 2001; TABER, 2001; ACEMOGLU; AUTOR, 2011). Beaudry, Green e Sand (2016) argumentam que uma "grande reversão" na demanda por habilidades cognitivas ${ }^{4}$ ocorreu no mercado de trabalho dos EUA em 2000 e Castex e Dechter (2014) descobriram que o retorno do mercado de trabalho às habilidades cognitivas era substancialmente menor nos anos 2000 do que na década de 1980.

Uma possível explicação é que o capital "computador" está substituindo o trabalho mais alto na distribuição de habilidades, já que os avanços na informatização redefinem o que significa que o trabalho seja "rotineiro" (LU, 2015), sugerindo que a polarização é uma fase intermediária, com o crescimento do emprego se parecendo mais com uma "rampa descendente" (AUTOR et al., 2014). Deming (2015) mostra que os trabalhos de rotina estão desaparecendo ainda mais na distribuição de habilidades. Novas tecnologias, como a aprendizagem automática, melhoraram drasticamente a capacidade de computadores para automatizar tarefas "cognitivas", levando ao receio de que a porção da mão-de-obra permaneça em declínio permanente à medida que os computadores substituem até os trabalhadores mais qualificados (BRYNJOLFSSON; MCAFEE, 2012; FREY; OSBORNE, 2017; AUTOR et al., 2014; KARABARBOUNIS; NEIMAN, 2013).

Entretanto, Deming (2015) revela que alguns tipos de trabalhos, caracterizados por serem altamente qualificados e difíceis de automatizar, exigem cada vez mais as chamadas habilidades sociais ou, de forma mais abrangente, as chamadas competências socioemocionais $^{5}$. A razão é que as habilidades envolvidas nas interações humanas são em grande parte baseadas no conhecimento tácito e, como argumenta Autor et al. (2014), os computadores ainda são substitutos muito fracos de tarefas onde os programadores não conhecem "as regras". A interação humana requer uma capacidade que os psicólogos chamam de "teoria da mente" - a habilidade de atribuir e representar, em si próprio e nos outros, os estados mentais independentes (crenças, intenções, desejos, conhecimento, etc) e de compreender que os outros possuem crenças, desejos e intenções que são distintas da sua própria, ou mais coloquialmente "colocar-se no lugar do outro"6 (BARON-COHEN,

4 O funcionamento cognitivo é definido como a capacidade de um indivíduo realizar as várias atividades mentais associadas à aprendizagem, compreensão, integração das informações de uma forma significativa e uma categoria ampla conhecida como habilidades executivas. Os exemplos de habilidades cognitivas incluem habilidades verbais, espaciais, psicomotoras e de velocidade de processamento. Desta forma, a cognição refere-se principalmente a coisas como a memória, a capacidade de aprender novas informações, fala e resolução de problemas.

5 A noção de competência consiste na junção e coordenação das habilidades com conhecimentos e atitudes que permitem a atuação efetivade uma pessoa em um trabalho ou atuação. A noção de habilidade, de forma mais restrita que a noção de competência, diz respeito a uma capacidade aprendida para realizar uma função ou obter um resultado desejado.

6 O progresso na automação da interação social é melhor exemplificado pelo contínuo fracasso do teste de Turing, que mede a capacidade de uma máquina exibir comportamento inteligente equivalente a um ser humano, ou indistinguível deste. O teste consiste na simulação de uma conversa humana por cinco minutos em uma configuração altamente controlada. No exemplo ilustrativo original, um jogador humano entra em uma conversa, em linguagem natural, com outro humano e uma máquina projetada 
2000; PREMACK; WOODRUFF, 1978; CAMERER; LOEWENSTEIN; PRELEC, 2005).

À medida em que surgem evidências internacionais de que o mercado de trabalho tem valorizado essas competências (WEINBERGER, 2014; BALCAR, 2014; DEMING, 2015), é oportuno questionar a validade dessas evidências para o mercado de trabalho brasileiro. Tendo em vista que são relativamente escassos os estudos que se propõem a analisar o papel das competências socioemocionais no mercado de trabalho brasileiro, bem como o amplo reconhecimento da necessidade de investigações mais detalhadas sobre o tema, o presente estudo tem o objetivo de trazer evidências do retorno associado à essas competências usando dados nacionais.

O estudo encontra-se organizado em 7 seções além desta introdução. A seção 1 busca apresentar o debate a respeito dos impactos recentes e perspectivas futuras do avanço tecnológico no trabalho e nas profissões. A seção 2 trata da crescente importância das competências socioemocionais no mercado de trabalho destacando as principais evidências internacionais a respeito do tema, seguida da seção 3 que apresenta as evidências existentes para o caso brasileiro e discute a contribuição do presente estudo. A seção 4 descreve os dados utilizados, seguida da seção 5 onde descrevemos a metodologia e as hipóteses a serem testadas. Na seção 6 os resultados são apresentados e interpretados, e por fim, na seção 7 fazemos nossas considerações finais.

para produzir respostas indistinguíveis de outro ser humano, tendo a terafa de ao final da conversa determinar qual respondente é o humano e qual é a máquina. Todos os participantes estão separados um dos outros. Turing propôs que uma máquina passaria no teste uma vez que poderia convencer um humano 70 por cento do tempo depois de cinco minutos de conversa. 


\section{Parte I}

\section{Referenciais teóricos}




\section{A Quarta Revolução Industrial e a escassez de talentos}

Onde quer que seja o lugar onde trabalhamos - no chão da fábrica ou no campo existe uma revolução silenciosa acontecendo. Desenvolvimentos nos campos da genética, biotecnologia, inteligência artificial, robótica, nanotecnologia e impressão 3D, entre outros, estão mudando radicalmente o mundo como o conhecemos e proporcionando novas oportunidades de combinações de trabalho físico, mental e mecânico, justificando para muitos o início de uma Quarta Revolução Industrial: a era da robótica avançada, automação no transporte, inteligência artificial e aprendizagem automática (BLOEM et al., 2014). Segundo Schwab (2017), estamos a bordo de uma revolução tecnológica com impactos profundos no âmbito social, e fundamentalmente, econômico.

Diversos estudos têm surgido com o intúito de entender os impactos dessa revolução tecnológica no trabalho e nas profissões (SUSSKIND; SUSSKIND, 2015; SCHWAB, 2017; FREY; OSBORNE, 2017). De acordo com o Future of Jobs Report, relatório elaborado pelo Fórum Econômico Mundial (SCHWAB; SAMANS, 2016), tal revolução tem impacto direto no mundo do trabalho, seja no surgimento ou desaparecimento de profissões, seja no rol de competências demandadas pelo mercado. Ao mesmo tempo que novas ocupações surgem e outras são ameaçados pela redundância de suas tarefas, os trabalhos existentes também estão passando por uma mudança no conjunto de habilidades necessário para fazê-los.

O debate sobre essas transformações é muitas vezes polarizado entre aqueles que prevêem novas oportunidades ilimitadas e aqueles que acreditam que tal revolução possa gerar distorções indesejáveis. O lado mais entusiasta desse diálogo argumenta que, assim como as revoluções que a precederam, a Quarta Revolução Industrial tem o potencial de aumentar os níveis de renda global e melhorar a qualidade de vida das populações, bem como conduzir as economias a um "milagre" do lado da oferta, com ganhos de longo prazo em eficiência e produtividade (SCHWAB, 2017). Por outro lado, existem aqueles que consideram que a revolução tecnológica poderia resultar em maior desigualdade, particularmente por conta de seu potencial para perturbar os mercados de trabalho em favor daqueles que melhor incorporam as novas tecnologias. À medida que a automação substitui o trabalho em toda a economia, o deslocamento líquido de trabalhadores pela tecnologia pode agravar o fosso entre os retornos ao capital e o retorno ao trabalho (BRYNJOLFSSON; MCAFEE, 2012), além de intensificar o chamado desemprego tecnológico (FREY; OSBORNE, 2017; PETERS, 2017).

O consenso é que tal transformação traz consigo grandes desafios que exigirão 
adaptação proativa por parte de corporações, governos, sociedades e indivíduos. Em diversas indústrias e países, muitas ocupações e especialidades não existiam a 10 ou até cinco anos atrás e o ritmo dessa mudança não parece desacelerar (SCHWAB; SAMANS, 2016). Em um cenário de rápidas mudanças em termos de trabalho, a capacidade de antecipar e alinhar os requisitos de habilidades futuras, o conteúdo das atividades e o efeito agregado sobre o emprego desperta a atenção de empresas, governos e indivíduos a fim de aproveitar plenamente as oportunidades que possam surgir e mitigar resultados indesejáveis.

As iniciativas que buscam entender e descrever essas transformações abordam o conhecimento de pessoas melhor posicionadas em observar a dinâmica do trabalho - Diretores de Recursos Humanos e Diretores de Estratégia - perguntando o que as atuais mudanças significam, especificamente para o emprego, em termos de habilidades e recrutamento. A Tabela 2, retirada de Lee (2013), apresenta um panorama das competências para o século XXI segundo iniciativas globais, ressaltando suas diretrizes comuns. Como bem apontado pelo autor, as competências enumeradas por essas iniciativas estão intimamente ligadas às chamadas competências socioemocionais ou "soft skills" (MONTGOMERY, 1997; HECKMAN; KAUTZ, 2012).

Tabela 2 - Panorama das Competências para o Século XXI segundo Iniciativas Globais

\begin{tabular}{|c|c|c|c|}
\hline P21 & ATC 215 & OECD & $\begin{array}{c}\text { European Reference } \\
\text { Framework }\end{array}$ \\
\hline $\begin{array}{l}\text { 1) Criatividade e inovação } \\
\text { 2) Pensamento crítico e } \\
\text { Resolução de Problemas }\end{array}$ & $\begin{array}{l}\text { Formas de Pensar } \\
\text { 1) Criatividade e inovação } \\
\text { 2) Pensamento crítico, } \\
\text { Resolução de Problemas e } \\
\text { Tomada de Decisão } \\
\text { 3) Aprender a aprender e } \\
\text { Metacognição }\end{array}$ & & 1) Aprender a aprender \\
\hline 3) Comunicação e Colaboração & $\begin{array}{l}\text { 4) Comunicação } \\
\text { 5) Colaboração } \\
\text { (trabalhar em equipe) }\end{array}$ & $\begin{array}{l}\text { 1) Relacionar com os Outros } \\
\text { 2) Trabalho Cooperativo em Equipe } \\
\text { 3) Arbitrar e Resolver Conflitos }\end{array}$ & $\begin{array}{l}\text { 2) Comunicação na Língua } \\
\text { Nativa } \\
\text { 3) Comunicação na Língua } \\
\text { Estrangeira }\end{array}$ \\
\hline $\begin{array}{c}\text { Informação, Mídia e } \\
\text { Conhecimento Tecnológico }\end{array}$ & Ferramentas para o Trabalho & Usar Ferramentas Interativamente & \\
\hline $\begin{array}{l}\text { 4) Alfabetização Informacional } \\
\text { 5) Alfabetização em Mídia } \\
\text { 6) Alfabetização Tecnológica (ICT) }\end{array}$ & $\begin{array}{l}\text { 6) Alfabetização Informacional } \\
\text { 7) Alfabetização Tecnológica (ICT) }\end{array}$ & $\begin{array}{l}\text { 4) Usar Textos e Símbolos de } \\
\text { Linguagem Interativamente } \\
\text { 5) Usar Conhecimento e } \\
\text { Informação Interativamente } \\
\text { 6) Usar Tecnologia } \\
\text { Interativamente }\end{array}$ & $\begin{array}{l}\text { 4) Competência Matemática e } \\
\text { Competências Básicas em Ciência } \\
\text { 5) Competência Digital }\end{array}$ \\
\hline $\begin{array}{l}\text { Talentos para a Carreira e para a Vida } \\
\text { 7) Flexibilidade e Adaptabilidade } \\
\text { 8) Iniciativa e Auto-Determinação } \\
\text { 9) Habilidade Social e Multicultural } \\
\text { 10) Produtividade e Prestar } \\
\text { Satisfação } \\
\text { 11) Liderança e Responsabilidade }\end{array}$ & $\begin{array}{l}\text { 8) Cidadania (Local e Global) } \\
\text { 9) Vida e Carreira } \\
\text { 10) Responsabilidade Pessoal e Social } \\
\text { (Incluindo Consciência, Sensibilidade e } \\
\text { Compreensão de Aspectos Culturais) }\end{array}$ & $\begin{array}{l}\quad \text { Agir de Forma Autônoma } \\
\text { 7) Agir Considerando o } \\
\text { Contexto Mais Amplo } \\
\text { 8) Formar e Conduzir os Planos } \\
\text { de Vida e Projetos Pessoais } \\
\text { 9) Defender e Afirmar Direitos, } \\
\text { Interesses, Limites e } \\
\text { Necessidades }\end{array}$ & $\begin{array}{l}\text { 6) Competências Cívicas e Sociais } \\
\text { 7) Senso de Iniciativa e } \\
\text { Empreendedorismo } \\
\text { 8) Consciência, Sensibilidade e } \\
\text { Expressões Culturais }\end{array}$ \\
\hline
\end{tabular}

Fonte: Lee (2013)

Entretanto, Cunningham e Villaseñor (2014) são francos em afirmar que, apesar dos empregadores valorizarem todos os conjuntos de habilidades, onde existe a maior demanda e a maior lacuna é no conjunto de competências socioemocionais. Esses resultados são robustos entre economias de diversos tamanhos e níveis de desenvolvimento, setores 
e ocupações. A demanda por trabalhadores qualificados combinado com a escassez de "talentos" resulta em grandes desafios de recrutamento por parte das empresas, uma constatação já evidente.

Scale (2016) ao pesquisar as preocupações de gerentes de contratação sugere que eles estão pelo menos tão preocupados com déficits em habilidades não cognitivas quanto com déficits em habilidades cognitivas. Enquanto menos de $20 \%$ dos gerentes de contratação disseram que os recém-formados não tinham as habilidades de matemática necessárias para o trabalho, mais de metade disse que os recém-formados careciam de atenção aos detalhes. Cerca de 50\% dos gerentes de contratação viram deficiências na proficiência de escrita e comunicação - aspectos cognitivos e não cognitivos, respectivamente, de uma única habilidade. Além disso, cerca de um terço desses gerentes relataram que os recém-formados universitários careciam de habilidades de análise de dados e trabalho em equipe.

Outra evidência vem do relatório mais recente do Hays Global Skills Index ${ }^{1}$ (HAYS, 2017) mostrando que apesar da ligeira suavização das pressões sobre o mercado de trabalhadores qualificados (queda do índice geral de 5,4 em 2016 para 5,3 em 2017), a diferença entre as competências que as empresas procuram e as competências disponíveis no mercado de trabalho continua sendo o principal desafio das economias mundiais (o índice de "incompatibilidade" de talentos manteve a pontuação de 6,4 relatada em 2016).

Em resumo, nessa seção apresentamos a discussão que existe acerca dos impactos da revolução tecnológica no trabalho e nas profissões. As leituras sobre tais impactos divergem quanto suas projeções, entretanto o consenso é que seus efeitos já podem ser sentidos e o momento para se alinhar a essas transformações e mitigar resultados indesejados é agora. Iniciativas globais apontam quais serão as competências profissionais necessárias para o século XXI, tais competências estão intimamente relacionadas com as chamadas competências socioemociocionais. Além disso, o descompasso da oferta de trabalhadores qualificados em relação a essas competências é tido como o principal desafio das economias mundiais.

Diversos estudos têm apontado para a crescente importância das "soft skills" em diversos resultados da vida de um indivíduo, em especial aqueles relacionados ao mercado de trabalho. A seção a seguir apresenta a literatura sobre o tema, suas principais evidências e implicações práticas relacionadas à questão da escassez de talentos.

1 O Hays Global Skills Index (o "Index") é uma avaliação anual das tendências que impactam os mercados de trabalho qualificados de 33 países, determinando como é fácil ou difícil para as organizações encontrarem os profissionais qualificados que precisam. Sete indicadores são calculados para tratar as questões de oferta e demanda de trabalhadores qualificados. Cada indicador mede a pressão do mercado de trabalho local em relação a um período de tranquilidade econômica. Escores mais altos significam que um país está passando por mais pressão do que historicamente tem sido o caso. Pontuações mais baixas significam que um país está sofrendo menos pressão. Combinados, formam um índice geral que resume as condições do mercado de trabalhadores qualificados. 


\section{A crescente importância das competências socioemocionais no mercado de trabalho}

Estudos recentes nos campos da educação, economia, psicologia e neurociência têm demonstrado que as "Soft skills" ${ }^{1}$ ou competências socioemocionais (social-emotional skills - SEMS) são tão importantes quanto as medidas cognitivas (QI ou inteligência fluida) em prever uma série de comportamentos sociais da vida do indivíduo (ZINS et al., 2004; HECKMAN; STIXRUD; URZUA, 2006; HECKMAN; KAUTZ, 2012). É bem documentado a relação entre essas competências com o rendimento escolar (O'CONNOR; PAUNONEN, 2007; POROPAT, 2009), saúde, cidadania, entre outros (PRIMI et al., 2016). Além disso, as competências socioemocionais promovem o aprendizado, interferindo na maneira como o indivíduo interpreta experiências (reflete sobre as experiências) e como extrai seus benefícios, haja vista os aspectos afetivos e motivacionais que influenciam na aprendizagem (SANTOS; PRIMI, 2014).

Da mesma forma, surgem fortes evidências da influência das competências socioemocionais na previsão de inserção ocupacional, salários e outros resultados do mercado de trabalho (HECKMAN; RUBINSTEIN, 2001; ALMLUND et al., 2011; LINDQVIST; VESTMAN, 2011), bem como no maior rendimento e menor estresse no ambiente laboral (CARMELI; JOSMAN, 2006; O'BOYLE et al., 2011). Segundo Schanzenbach et al. (2016), o desenvolvimento de habilidades não cognitivas é fundamental para promover o sucesso no mercado de trabalho, porque:

- Os empregos de hoje exigem mais habilidades não cognitivas do que os empregos no passado (AUTOR; LEVY; MURNANE, 2003; DEMING, 2015);

- O mercado de trabalho premia cada vez mais as habilidades não cognitivas (WEINBERGER, 2014; BALCAR, 2014; DEMING, 2015);

- Aqueles com menos habilidades não cognitivas estão sendo deixados para trás (HECKMAN; RUBINSTEIN, 2001).

Tem sido convincentemente defendido que, assim como as habilidades cognitivas, as habilidades não cognitivas são mais maleáveis na infância (CUNHA; HECKMAN; SCHENNACH, 2010). Entretanto, estudos recentes tem mostrado que políticas ativas e investimentos que ocorrem na adolescência ou na juventude podem impulsionar o desenvolvimento de habilidades não cognitivas (BRUNELLO; SCHLOTTER, 2011; CRÉPON;

1 Esses conceitos abrangem habilidades maleáveis e sensíveis a experiências e interação com as outras pessoas, por isso o termo "soft", em contraposição aos menos maleáveis. 
BERG, 2016). Embora ainda haja imprecisão quanto ao lapso de intervenção nessa área, a janela de oportunidade para influenciar o desenvolvimento de habilidades não cognitivas é significativamente mais ampla que para as habilidades cognitivas.

Essas descobertas têm implicações práticas de importância crucial para a questão de escassez de talentos no mercado de trabalho. Busso et al. (2012) alertam para a preparação do jovem para o mercado de trabalho no século XXI e questionam se o sistema educacional está realmente cumprindo seu papel de facilitador dessa transição. Uma das principais conclusões dos autores é que o despreparo dos jovens ingressantes no mercado reflete, em parte, uma lacuna existente entre as competências que se adquire na escola e aquelas exigidas pelo mercado de trabalho.

Mais do que isso, dentre as centenas de competências existentes não é claro quais são aquelas que podem ser classificadas como prioridade e devem ser incluídas nas propostas curriculares. De acordo com Guerra, Modecki e Cunningham (2014), apesar das diversas listas de habilidades desejadas para o mercado de trabalho, existe pouco consenso sobre quais são as competências prioritárias e como ensiná-las. Cunningham e Villaseñor (2014) identificaram aproximadamente 140 "soft skills" desejadas ao revisar estudos internacionais sobre a demanda dos empregadores por habilidades.

Em síntese, buscamos mostrar nessa seção que o desenvolvimento das competências socioemocionais é tido por diversas áreas do conhecimento como instrumento que desempanha importante papel em uma série de dimensões sociais e econômicas. Tratando-se do mercado de trabalho, as competências socioemocionais são fortemente relacionadas com medidas de sucesso como altos salários e empregabilidade. Além disso, por possuírem uma janela de desenvolvimento significamente mais ampla que as habilidades cognitivas, as competências socioemocionais podem ser impulsionadas na juventude, entretanto não é claro qual o conjunto de habilidades que se deve ser priorizado.

O quadro até aqui apresentado reflete as principais questões discutidas na literatura internacional, porém não explora a realidade brasileira. A seção a seguir busca rescolher o que se sabe da relação entre o rol de habilidades discutido até aqui e o mercado de trabalho brasileiro, bem como apresentar as contribuições desse estudo para levantar mais evidências sobre o tema. 


\section{Evidências para o caso brasileiro}

Boa parte da literatura empírica que examina a relação das competências socioemocionais com o mercado de trabalho, principalmente no que diz respeito ao retorno associado à essas competências (DEMING, 2015), utiliza dados de países desenvolvidos que contêm informações detalhadas sobre habilidades, conhecimento e atividades de trabalho necessárias em uma ocupação. Para os países em desenvolvimento, como o Brasil, a disponibilidade de dados com tal detalhamento é muito mais restrita, o que explica o fato dessa literatura ser relativamente escassa.

Entretanto, artigos do campo da psicologia e da administração reconhecem as habilidades não congnitivas como fator-chave para o bom desempenho no trabalho e detalham o processo de aquisição e desenvolvimento de competências profissionais (BENDASSOLLI; MALVEZZI, 2013; GONDIM; MORAIS; BRANTES, 2014). Gondim, Morais e Brantes (2014) argumenta que as competências socioemocionais tem papel relevante no desenvolvimento de competências para o trabalho, que não são atributos inatos, mas capacidades adquiridas ao longo do processo de socialização familiar, educacional e profissional. Bolsoni-Silva et al. (2006) admite que o amplo reconhecimento das habilidades sociais como requisito da competência e do sucesso profissional supõe a possibilidade de investigações mais detalhadas sobre essa temática, com outros grupos de formação ou atuação em diferentes áreas.

De forma a trazer evidências da relevância do estudo desse tema para o contexto brasileiro, buscamos identificar na Classificação Brasileira de Ocupações (CBO) quais foram as competências mais citadas entre quase 600 famílias ocupacionais que compõem o documento. A Classificação Brasileira de Ocupações (CBO) é o documento que reconhece, nomeia e codifica os títulos e descreve as características das ocupações do mercado de trabalho brasileiro. Sua atualização e modernização se devem às profundas mudanças ocorridas no cenário cultural, econômico e social do País nos últimos anos, retratando alterações estruturais no mercado de trabalho. Uma grande novidade da edição mais recente da CBO é a listagem das competências pessoais necessárias para o exercício de cada família ocupacional, incluindo habiliades cognitivas e não cognitivas.

As competências de cada família ocupacional foram catalogadas em um banco de dados, onde se verificou a existência de 3454 títulos, muitos deles sendo títulos sinônimos que poderiam ser agrupados em uma única categoria. Um intenso esforço foi feito para limpar a repetição dos títulos sinônimos, reduzindo a lista de competências para 1051 títulos. A tabela 3 apresenta as 40 competências mais citadas pelas famílias ocupacionais presentes na $\mathrm{CBO}$. 
Alguns títulos como "Atualizar-se profissionalmente", "Demonstrar habilidade manual" e "Demonstrar capacidade de raciocínio lógico" estão mais relacionadas com habilidades motoras e cognitivas. Por outro lado, entre os quinze títulos mais citadas na CBO, quatorze estão intimamente relacionadas com algum tipo de competência socioemocional, demonstrando a importância estudar a fundo o papel dessas competências no contexto do mercado de trabalho brasileiro.

Sob a luz das evidências até aqui apontadas, este estudo tem o objetivo de investigar a relação entre as competências socioemocionais e o mercado de trabalho no contexto da economia brasileira. Motivados pelas transformações tecnológicas recentes e a crescente importância das competências socioemocionais, bem como a insuficiência de estudos que tratem sobre o tema para o caso brasileiro, procuramos colaborar com a discussão norteando as seguintes questões:

1. Existe um retorno associado às competências socioemocionais no mercado de trabalho brasileiro?

2. É possível que esse retorno seja diferente entre grupos de ocupação?

Acreditamos que ao se debruçar sobre essas questões estaremos colaborando com a literatura sobre o tema no sentido de inserir o Brasil no debate, bem como colaborando com as esferas públicas ao prover evidências que podem ser usadas para direcionar intervenções integradas com as demandas do mercado de trabalho brasileiro. 
Tabela 3 - As habilidades mais citadas na Classificação Brasileira de Ocupações

\begin{tabular}{|c|c|}
\hline Habilidade & $\begin{array}{l}\text { Quantidade } \\
\text { de citações }\end{array}$ \\
\hline 1 - Trabalhar em equipe & 343 \\
\hline 2 - Demonstrar iniciativa & 256 \\
\hline 3 - Manifestar criatividade & 246 \\
\hline 4 - Demonstrar capacidade de organização & 187 \\
\hline 5 - Exercer liderança & 185 \\
\hline 6 - Demonstrar capacidade de comunicação & 184 \\
\hline 7 - Atualizar-se profissionalmente & 173 \\
\hline 8 - Adaptar-se a circunstâncias e situações variadas & 166 \\
\hline 9 - Assumir responsabilidades & 141 \\
\hline 10 - Demonstrar capacidade de auto-controle & 117 \\
\hline 11 - Manter postura ética e moral & 114 \\
\hline 12 - Demonstrar capacidade de decisão & 109 \\
\hline 13 - Agir com dinamismo & 95 \\
\hline 14 - Demonstrar capacidade de relacionamento interpessoal & 87 \\
\hline 15 - Demonstrar paciência & 86 \\
\hline 16 - Demonstrar percepção (feeling) & 85 \\
\hline 17 - Revelar capacidade de concentração & 82 \\
\hline 18 - Demonstrar habilidade manual & 76 \\
\hline 19 - Demonstrar habilidade de negociar & 72 \\
\hline 20 - Demonstrar capacidade de raciocínio lógico & 70 \\
\hline 21 - Demonstrar e transmitir segurança & 67 \\
\hline 22 - Demonstrar condicionamento físico para executar a função & 65 \\
\hline 23 - Demonstrar conhecimento de língua estrangeira & 57 \\
\hline 24 - Demonstrar capacidade de lidar com situações adversas & 55 \\
\hline 25 - Resolver conflitos & 53 \\
\hline 26 - Demonstrar senso crítico & 52 \\
\hline 27 - Demonstrar capacidade de cumprir regras e normas & 49 \\
\hline 28 - Argumentar com convicção (persuasão) & 49 \\
\hline 29 - Demonstrar disciplina & 49 \\
\hline 30 - Demonstrar acuidade sensorial & 44 \\
\hline $\begin{array}{l}31 \text { - Demonstrar capacidade para o uso de aplicativos } \\
\text { e programas de informática }\end{array}$ & 44 \\
\hline 32 - Evidenciar objetividade & 43 \\
\hline 33 - Demonstrar capacidade de trabalhar sob pressão & 43 \\
\hline 34 - Demonstrar empatia & 42 \\
\hline 35 - Desenvolver capacidade de observação & 40 \\
\hline 36 - Ser sociável & 40 \\
\hline 37 - Demonstrar capacidade de resolução de problemas & 39 \\
\hline 38 - Demonstrar visão espacial & 39 \\
\hline 39 - Demonstrar acuidade visual & 38 \\
\hline 40 - Demonstrar capacidade de auto-desenvolvimento (aperfeiçoar-se) & 36 \\
\hline
\end{tabular}

Fonte: Classificação Brasileira de Ocupações (CBO). 
Parte II

Estratégia Empírica 


\section{Dados}

Os microdados utilizados nesse estudo são provenientes do Indicador de Alfabetismo Funcional (Inaf) de 2015 que conta de forma pioneira com uma aplicação de instrumentos de mensuração de competências socioemocionais em indivíduos em idade ativa ${ }^{1}$. O Indicador de Alfabetismo Funcional (Inaf) constitui-se de um survey idealizado em parceria entre o Instituto Paulo Montenegro e a ONG Ação Educativa² - com o apoio do IBOPE Inteligência - que articula testes cognitivos com questionários de contextualização sociodemográfica, econômica, cultural e educacional com o objetivo maior de mensurar o nível de alfabetismo da população brasileira entre 15 e 64 anos, avaliando suas habilidades e práticas de leitura, de escrita e de matemática aplicadas ao cotidiano.

A coleta de dados é feita através de entrevistas domiciliares e a amostra é estratificada com alocação proporcional à população brasileira em cada região. Dentro de cada uma das regiões, são selecionadas amostras probabilísticas em três estágios (sorteio de municípios e setores censitários, por meio do método Probabilidade Proporcional ao Tamanho) e seleção de pessoas a serem entrevistadas por cotas proporcionais segundo sexo, idade, escolaridade e condição de ocupação. O universo considerado é, portanto, a totalidade das pessoas jovens, adultas e idosas com idade entre 15 e 64 anos, residentes tanto de zonas rurais quanto urbanas do Brasil.

De acordo com o relatório produzido pelo Instituto Paulo Montenegro e a ONG Ação Educativa (LIMA; RIBEIRO; CATELLI, 2015), foram entrevistadas 2.002 pessoas residentes em zonas urbanas e rurais de todas as regiões do país, sendo que as mulheres representam $52 \%$ e os homens, $48 \%$ da população pesquisada. Do total, $46 \%$ se declararam pardos, $38 \%$ brancos, $13 \%$ pretos e apenas $2 \%$ amarelos ou indígenas. Em termos educacionais, $44 \%$ declararam estar cursando ou ter cursado até o ensino fundamental, $40 \%$ o ensino médio e apenas $17 \%$ a educação superior. Da amostra, $63 \%$ informaram estar trabalhando (desses, $24 \%$ estavam no setor de comércio, 10\% na construção, 10\% nos serviços domésticos e $10 \%$ na indústria) $10 \%$ desempregados(as), $3 \%$ procuravam o primeiro emprego, $5 \%$ estavam aposentados(as) e 7\% estavam em situações como pensionista, viviam de renda ou nunca haviam trabalhado e nem estava procurando emprego; $11 \%$ estavam na condição de dona de casa.

Três competências socioemocionais foram medidas na pesquisa de 2015: Abertura

1 De acordo com o IBGE, a população considerada em idade economicamente ativa compreende indivíduos com 15 anos ou mais de idade.

2 Ao longo de quase 15 anos, o Instituto Paulo Montenegro consolidou, em parceria com a ONG Ação Educativa, 9 edições do Indicador de Alfabetismo Funcional, reafirmando seu papel como provedor de informações qualificadas sobre o campo educacional, capazes de fomentar o debate público, estimular iniciativas da sociedade civil e subsidiar a formulação de políticas nas áreas de educação e cultura. 
ao Novo (curiosidade para aprender, imaginação criativa, interesse artístico), Autogestão (responsabilidade, determinação, persistência, foco, organização) e Autoconceito (estabilidade emocional, autoestima, autoconfiança e protagonismo). Duas das habilidades que compõem o Inaf 2015, Abertura ao Novo e Autogestão, pertencem ao modelo dos Cinco Grandes Fatores da Psicologia ( The Big Five Model $^{3}$ ) e são medidas através do instrumento Social and Emotional (or Noncognitive) Nationwide Assessment - SENNA (SANTOS; PRIMI, 2014). Já a competência relacionada ao autoconceito foi medida pela Escala Core self-evaluations - CSE (JUDGE et al., 2003). A Tabela 4 resume as principais características associadas às três competências socioemocionais observadas no Inaf 2015.

A justificativa para a escolha dessas três competências, segundo os idealizadores da pesquisa, é embasada na íntima relação dessas habilidades com estudos, trabalho, renda, saúde e bem-estar na vida adulta, ou o que tem sido identificado por estudiosos como "competências do século XXI", ou aquelas habilidades particularmente relevantes para a vida neste século (Tabela 2). Em relatório produzido pelo eduLab21 em parceria com o Instituto Paulo Montenegro e a Rede Conhecimento Social ${ }^{4}$, as propriedades de medidas psicométricas dos instrumentos socioemocionais do Inaf foram avaliadas e apresentaram boas características psicométricas na amostra. De modo geral, as medidas socioemocionais alcançaram resultados entre aceitáveis e ótimos nos índices de confiabilidade.

Além das medidas socioeconômicas e socioemocionais, outras informações essencias para nossa análise é a situação atual de trabalho, o salário dos indivíduos e a ocupação principal atual. Para nosso estudo, restringimos a amostra à população com idade entre 25 e 65 anos que autodeclaram estarem trabalhando. A escolha de não incluir jovens com menos de 25 anos de idade na análise é devido à tentativa de examinar o panorama de indivíduos já consolidados no mercado de trabalho, engajados em suas carreiras e em suas ocupações.

As informações do Inaf 2015 não permitem identificar a ocupação de cada indivíduo, o que seria um nível preferível de análise, porém qualifica 16 grupos de ocupações principais, nomeados na Tabela 5. Devido ao pequeno número de observações nos sete primeiros grupos de ocupações, optou-se por agregar os itens de caráter público e privado em três: Função de direção e gerência; Função de coordenação, supervisão, técnico especialista, assessor ou

3 Nas últimas décadas, manifestou-se entre os psicólogos um consenso de que os comportamentos humanos associados a traços de personalidade se agrupam em cinco dimensões, conhecidas como os Cinco Grandes Domínios de personalidade (Big Five): Abertura a Novas Experiências, Extroversão, Amabilidade, Conscienciosidade e Estabilidade Emocional. Os Big Five são construtos latentes obtidos por análise fatorial realizada sobre respostas de amplos questionários com perguntas diversificadas sobre comportamentos representativos de todas as características relativamente estáveis de personalidade que um indivíduo poderia ter. Quando aplicados a pessoas de diferentes culturas e em diferentes momentos do tempo, esses questionários demonstraram ter a mesma estrutura fatorial, dando origem à hipótese de que os traços de personalidade dos seres humanos se agrupariam efetivamente em torno de cinco grandes domínios. No Brasil, inclusive, ele já foi utilizado por equipes de pesquisadores em diferentes estados do país (PRIMI et al., 2016).

4 Ver <http://www.institutoayrtonsenna.org.br/como-atuamos/inovacao/estudos-e-pesquisas/> 
Tabela 4 - As três competências socioemocionais avaliadas no INAF

Escala Competência

\begin{tabular}{|l|l|}
\hline \multicolumn{1}{|c|}{ Escala } & \multicolumn{1}{c}{ Competência } \\
Essa escala mensura a tendência a ser imaginativo, curioso e interessado \\
em aprender. Refere-se a abertura para experimentar e pensar sobre \\
uma gama diversa de experiências perceptivas, cognitivas e afetivas. A \\
escala inclui questões sobre imaginação criativa: capacidade de gera- \\
ção de novas maneiras de pensar e agir por meio da experimentação, \\
brincadeira, aprendizagem; questões sobre curiosidade para aprender: \\
interesse em ideias, paixão por aprender, mentalidade inquisitiva que \\
facilita o pensamento crítico e a resolução de problemas; e interesse \\
artístico: interesse em avaliar, apreciar e valorizar design, arte, música, \\
beleza, e outras.
\end{tabular}

1. Escalas adaptadas do SENNA v1: Primi et al. (2016).

2. Escala Core self-evaluations (CSE): Judge et al. (2003).

equivalente, professor, médico, advogado; e Função operacional, não especialista, assistente, operador ou equivalente. O grupo referênte a estagiários e treinees do setor privado, além do pequeno número de observações em nossa amostra (apenas duas observações), representa indivíduos ainda estão passando por fase de treinamento e não estão consolidados no mercado de trabalho. Dessa forma, foram desconsiderados da análise. 
Tabela 5 - Ocupação principal atual - INAF 2015

1 - SETOR PÚBLICO: Função de direção e gerência

2 - SETOR PÚBLICO: Função de coordenação, supervisão, técnico especialista, assessor ou equivalente, professor, médico, advogado

3 - SETOR PÚBLICO: Função operacional, não especialista, assistente, operador ou equivalente

4 - SETOR PRIVADO: Função de direção, gerência

5 - SETOR PRIVADO: Função de coordenação, supervisão, técnico especialista, assessor ou equivalente, professor, médico, advogado

6 - SETOR PRIVADO: Função operacional, não especialista, assistente, operador ou equivalente

7 - SETOR PRIVADO: Estagiário, trainee

8 - Empresário, Grande proprietário rural, Criador, Industrial, empregador, investidor

9 - Microempresário

10 - Especialista, prestador de serviços de nível superior (advogado, médico, arquiteto, engenheiro, contador, dentista)

11 - Especialista, prestador de serviços de nível técnico (representante comercial, vendedor, mecânico, instalador, atleta)

12 - Conta própria em casa sem carteira (confecção, produção de alimentos, manicure ou equivalente)

13 - Conta própria fora de casa sem carteira (camelô, ambulante, biscate, bico, boia fria ou equivalente)

14 - Pequeno produtor rural, criador

15 - Serviço doméstico com carteira assinada

16 - Serviço doméstico sem carteira assinada

Fonte: Elaboração própria

A Tabela 6 apresenta a distribuição dos grupos de ocupações principais após a agregação mencionada acima. Nota-se que o número de observações encontradas para alguns grupos foram baixas e talvez isso possa se traduzir em um problema de representatividade.

A informação de salário dos indivíduos foi construída a partir das questões do questionário a respeito da remuneração recebida no último mês ${ }^{5}$, podendo o respondente optar por não informar seu rendimento. A Tabela 7 mostra que os indivíduos da amostra estão distribuídos por todas as regiões do Brasil.

$\overline{5}$ No dicionário das variáveis do INAF 2015, as questões referêntes ao rendimento auferido no último mês não distingue aquela derivada do trabalho e a não derivada do trabalho 
Tabela 6 - Distribuição dos grupos de ocupação - INAF 2015

\begin{tabular}{|c|c|c|c|}
\hline Ocupação principal atual & Freq & $\begin{array}{l}\text { Porcent } \\
\quad(\%)\end{array}$ & $\begin{array}{l}\text { Porcent } \\
\text { Acum }(\%)\end{array}$ \\
\hline 1 - Função de direção e gerência & 16 & 2,19 & 2,19 \\
\hline $\begin{array}{l}2 \text { - Função de coordenação, supervisão, técnico especia- } \\
\text { lista, assessor ou equivalente, professor, médico, advogado }\end{array}$ & 56 & 7,66 & 9,85 \\
\hline $\begin{array}{l}3 \text { - Função operacional, não especialista, assistente, ope- } \\
\text { rador ou equivalente }\end{array}$ & 267 & 36,53 & 46,47 \\
\hline $\begin{array}{l}4 \text { - Empresário, Grande proprietário rural, Criador, In- } \\
\text { dustrial, empregador, investidor }\end{array}$ & 11 & 1,50 & 47,88 \\
\hline 5 - Microempresário & 31 & 4,24 & 52,12 \\
\hline $\begin{array}{l}6 \text { - Especialista, prestador de serviços de nível superior } \\
\text { (advogado, médico, arquiteto, engenheiro, contador, den- } \\
\text { tista) }\end{array}$ & 9 & 1,23 & 53,35 \\
\hline $\begin{array}{l}7 \text { - Especialista, prestador de serviços de nível técnico } \\
\text { (representante comercial, vendedor, mecânico, instalador, } \\
\text { etc)/atleta }\end{array}$ & 61 & 8,34 & 61,70 \\
\hline $\begin{array}{l}8 \text { - Conta própria em casa sem carteira (confecção, pro- } \\
\text { dução de alimentos, manicure ou equivalente) }\end{array}$ & 75 & 10,26 & 71,96 \\
\hline $\begin{array}{l}9 \text { - Conta própria fora de casa sem carteira (camelô, } \\
\text { ambulante, biscate, bico, boia fria ou equivalente) }\end{array}$ & 105 & 14,36 & 86,32 \\
\hline 10 - Pequeno produtor rural, criador & 38 & 5,20 & 91,52 \\
\hline 11 - Serviço doméstico com carteira assinada & 20 & 2,74 & 94,25 \\
\hline 12 - Serviço doméstico sem carteira assinada & 42 & 5,75 & 100,0 \\
\hline Total & 731 & 100 & \\
\hline
\end{tabular}

Fonte: Inaf (2015)

Tabela 7 - Distribuição da amostra por regiões brasileiras

\begin{tabular}{c|ccc} 
Regiões Brasileiras & Freq & $\begin{array}{c}\text { Porcent } \\
\mathbf{( \% )}\end{array}$ & $\begin{array}{c}\text { Porcent } \\
\text { Acum (\%) }\end{array}$ \\
\hline Norte & 50 & 6,84 & 6,84 \\
Nordeste & 217 & 29,69 & 36,53 \\
Centro-Oeste & 51 & 6,98 & 43,50 \\
Sudeste & 312 & 42,68 & 86,18 \\
Sul & 101 & 13,82 & 100 \\
\hline Total & 731 & 100 &
\end{tabular}

Fonte: INAF (2015) 


\section{Metodologia}

De acordo com Heckman e Rubinstein (2001), é surpreendente que as discussões acadêmicas sobre habilidade e formação de habilidades se concentrem quase exclusivamente em medidas de capacidade cognitiva e ignorem habilidades não-cognitivas ${ }^{1}$. A negligência das habilidades não cognitivas nas análises de rendimentos, escolaridade e outros resultados no tempo de vida foi devida principalmente à falta de qualquer medida confiável delas. Heckman e Kautz (2012) mostram que as medidas de capacidade cognitiva como avaliações de desempenho acadêmico ou testes de QI falham, ou não capturam adequadamente todo o conjunto de habilidades de um indivíduo, mais especificamente as chamadas soft skills.

Um grande esforço vindo do campo da psicologia buscou desenvolver baterias de testes para medir habilidades não cognitivas (JOHN; DONAHUE; KENTLE, 1991, p. ex). Muitoa desses testes são usualmente utilizados por empresas para examinar seus trabalhadores, e recentemente têm sido usados também para investigar a relação entre características socioemocionais e o aprendizado. Em particular, um recente instrumento de mensuração de atributos socioemocionais foi desenvolvido no Brasil, o Social and Emotional (or Noncognitive) Nationwide Assessment - SENNA (SANTOS; PRIMI, 2014). O instrumento foi criado buscando satisfazer duas características centrais: ser economicamente víavel para ser aplicado em larga escala e cientificamente robusto para subsidiar pesquisas acadêmicas.

Buscamos explorar a aplicação deste instrumento em indivíduos de idade ativa para investigar as relações entre as competências socioemocionais e o salário ${ }^{2}$. Para isso, além de apresentar estatísticas descritivas básicas, utilizamos como referência a especificação de salários baseados em características observáveis e habilidades latentes tal qual proposta por Heckman, Stixrud e Urzua (2006), porém através de uma abordagem mais simples.

Os autores postulam a existência de dois fatores subjacentes que representam a capacidade latente cognitiva e não cognitiva dos indivíduos. Condicionando os observáveis, esses fatores explicam toda a dependência entre escolhas e resultados ${ }^{3}$. Os níveis dos fatores de um indivíduo podem resultar de alguma combinação de habilidade herdada, a qualidade do ambiente fornecida por seus pais, seus primeiros esforços e os efeitos de qualquer intervenção precoce. Assume-se então que os níveis de ambos os fatores são conhecidos por cada indivíduo, mas não pelo pesquisador, e que eles são fixados pelo tempo que o indivíduo faz suas escolhas e escolhas de comportamento.

\footnotetext{
1 A literatura clássica de capital humano (BECKER, 1994, p. ex), contrastou os modelos de ganhos de capacidade cognitiva com modelos de capital humano, ignorando inteiramente os traços não cognitivos.

2 A seção 4 irá apresentar a base de dados utilziada nesse estudo.

3 Os autores assumem que as habilidades cognitivas e não-cognitivas determinam o salário do indivíduo, sua escolaridade, empregabilidade, experiência de trabalho e suas decisões profissionais.
} 
Seja $f^{C}$ e $f^{N}$ os níveis latentes de habilidades cognitivas e não cognitivas, respectivamente. O pressuposto de que um único fator latente capta a capacidade cognitiva é tradicional na literatura (HECKMAN, 1995, p. ex). Por sua vez, a suposição de que um único fator latente capta a capacidade não cognitiva é menos tradicional. Uma vez que existem muitos aspectos das habilidades não cognitivas - autocontrole, cooperatividade, sociabilidade, etc. - é menos provável que apenas um traço capte todos os aspectos desses comportamentos. No entanto, considerar um único fator para habilidades não cognitivas é um ponto de partida útil ao ponto que podemos avaliar a capacidade informativa de sua inclusão. Desta forma, o salário do indivíduo $i$ pode ser dado por uma especificação linear em parâmetros:

$$
\ln \left(Y_{i}\right)=\beta X_{i}+\gamma^{C} f_{i}^{C}+\gamma^{N} f_{i}^{N}+\epsilon_{i}
$$

onde $X_{i}$ é um vetor de variáveis de controle observáveis, $\beta$ é o vetor de retornos associados (incluindo intercepto) a $X_{i}, \gamma^{C}$ e $\gamma^{N}$ são os retornos associados ao fator cognitivo e não cognitivo, respectivamente, e $\epsilon_{i}$ representa o termo de erro idiossincrático tal que $\epsilon_{i} \Perp\left(f^{C}, f^{N}, X_{i}\right)$.

A partir dessa especificação, pode-se responder se existe evidência de retornos associados às competências socioemocionais para o mercado de trabalho brasileiro por meio de alguns exercícios. Primeiramente, podemos considerar um modelo mais restrito que não incorpora ambos os fatores latentes de habilidades cognitivas e não cognitivas $\left(\gamma^{C}=\gamma^{N}=0\right)$, aos moldes dos modelos de capital humano das décadas de 1960 e 1970 . Em seguida, podemos estimar um modelo menos restrito que incorpora o fator cognitivo porém ignora o fator não cognitivo $\left(\gamma^{N}=0\right)$ e ainda considerar um modelo sem restrição que incorpora ambos os fatores. A comparação desses modelos nos permite averiguar o ganho explicativo que se obtém ao se incluir os novos regressores. Além disso, pretendemos analisar a significância do parâmetro associado ao fator não cognitivo testando a seguinte hipótese:

$$
H_{0}: \gamma^{N}=0
$$

A base de dados utilizada nesse estudo, apresentada na seção 4, possui mais de uma medida socioemocional disponível. Sendo assim, ao considerar mais de um fator não cognitivo no modelo, a equação (5.1) pode ser reescrita como se segue:

$$
\ln \left(Y_{i}\right)=\beta X_{i}+\gamma^{C} f_{i}^{C}+\gamma^{N 1} f_{i}^{N 1}+\cdots+\gamma_{Y}^{N k} f_{i}^{N k}+\epsilon_{i}
$$

na qual $f_{i}^{N 1}, \cdots, f_{i}^{N k}$ representam os os níveis latentes de $k$ habilidades não cognitivas e $\gamma^{N 1}, \cdots, \gamma^{N k}$ seus retornos associados. Desta forma, incluímos nesse primeiro exercício um modelo que considera a presença de três fatores não cognitivos e comparamos com os demais para averiguar o comportamento do modelo. Assim como feito anteriormente, 
testaremos a significância dos retornos encontrados para esses fatores. Um teste conjunto de significância será construído sobre a seguinte hipótese:

$$
H_{0}: \gamma^{N 1}=\gamma^{N 2}=\gamma^{N 3}=0
$$

Outro exercício de interesse busca verificar se existe heterogeneidade no retorno relacionado às habilidades não cognitivas entre diferentes grupos de ocupação, tendo em vista que elas podem ser precificadas de forma distinta em diferentes atividades. Podemos recuperar o retorno de habilidades não cognitivas por grupo de ocupação incluindo dummies de grupo de ocupação e interações com o score socioemocional da seguinte maneira:

$$
\begin{aligned}
\ln \left(Y_{i}\right)= & \beta X_{i}+\gamma^{C} f_{i}^{C}+\gamma^{N} f_{i}^{N}+\lambda^{1} d \_o c u p_{i}^{1}+\cdots+\lambda^{j-1} d \_o c u p_{j-1}^{1}+ \\
& \delta_{1} d \_ \text {ocup } p_{i}^{1} * f_{i}^{N}+\cdots+\delta_{j-1} d \_ \text {ocup }{ }_{i}^{j-1} * f_{i}^{N}+\epsilon_{i}
\end{aligned}
$$

onde $d \_$ocup $p_{i}^{1}, \cdots, d \_o c u p_{i}^{j-1}$ são as dummies de ocupação ${ }^{4}, \lambda^{1}, \cdots, \lambda^{j-1}$ seus coeficientes associados e $\delta_{1}, \cdots, \delta_{j-1}$ representam os coeficientes associados às interações ${ }^{5}$. Para cada medida socioemocional presente em nossa base de dados, estimamos um modelo seguindo a especificação da equação (5.3). Ao comparar, por competência, os retornos associados a cada grupo de ocupação, $\delta_{1}, \cdots, \delta_{j-1}$, podemos verificar se dentro de determinado grupo de ocupação, pessoas com maior score socioemocional recebem maiores salários, tudo o mais constante. Neste caso, a significância de cada um desses termos, individualmente, será informativa sobre a heterogeneidade do retornos dentro de cada ocupação. Sem dúvida, pode existir seleção amostral por habilidades em cada ocupação, ou seja, um indivíduo pode compor certo grupo de ocupação justamente por possuir as competências necessárias para aquela atuação. Isso explicaria, por exemplo, retornos estatisticamente não diferentes de zero.

4 Um grupo de ocupação deve ser sempre omitido por conta da multicolinearidade.

5 As estimativas do tipo de erro padrão reportado permitem a correlação intragrupo (cluster) entre os diversos grupos de ocupação. 
Parte III

Resultados 


\section{Resultados}

Para tratar das questões relativas ao retorno que as competências socioemocionais possuem no mercado de trabalho brasileiro, apresentamos inicialmente algumas estatísticas descritivas dos dados no intuito de detectar possíveis relações entre as variáveis de interesse. Procuramos identificar o salário mensal médio por grupo de ocupação a fim de elencar as atividades mais rentáveis. Na Tabela 8 podemos constatar que, em geral, os grupos de ocupação mais rentáveis são atividades que parecem exigir um grau de especialização maior em comparação com os grupos com menor salário mensal médio.

Tabela 8 - Estatísticas salariais por Grupo de Ocupação (em R\$)

\begin{tabular}{|c|c|c|c|c|c|c|}
\hline $\begin{array}{l}\text { Grupo de } \\
\text { Ocupação }\end{array}$ & Descrição & Obs & Média & DP & Min & Max \\
\hline 5 & Microempresário & 31 & 2458,45 & 3029,90 & 780 & 15760 \\
\hline 6 & $\begin{array}{l}\text { Especialista, prestador de serviços } \\
\text { de nível superior (advogado, médico, } \\
\text { arquiteto, engenheiro, contador, den- } \\
\text { tista, etc) }\end{array}$ & 9 & 2286 & 2332,90 & 700 & 7880 \\
\hline 1 & $\begin{array}{l}\text { Função de direção, gerência } \\
\text { Função de coordenação, supervisão, }\end{array}$ & 16 & 2271 & 1711,91 & 450 & 6304 \\
\hline 2 & $\begin{array}{l}\text { técnico especialista, assessor ou equi- } \\
\text { valente, professor, médico, advogado, } \\
\text { etc }\end{array}$ & 56 & 1763,21 & 1127,32 & 780 & 6304 \\
\hline 4 & $\begin{array}{l}\text { Empresário, Grande proprietário ru- } \\
\text { ral, Criador, Industrial, empregador, } \\
\text { investidor }\end{array}$ & 11 & 1470,18 & 1552,24 & 700 & 6016 \\
\hline 7 & $\begin{array}{l}\text { Especialista, prestador de serviços } \\
\text { de nível técnico (representante co- } \\
\text { mercial, vendedor, mecânico, insta- } \\
\text { lador, etc) }\end{array}$ & 61 & 1347,09 & 1038,11 & 200 & 6316 \\
\hline 3 & $\begin{array}{l}\text { Função operacional, não especialista, } \\
\text { assistente, operador ou equivalente }\end{array}$ & 267 & 1343,37 & 1027,78 & 200 & 11820 \\
\hline 9 & $\begin{array}{l}\text { Conta própria fora de casa sem car- } \\
\text { teira (camelô, ambulante, biscate, } \\
\text { bico, boia fria ou equivalente) }\end{array}$ & 105 & 1108,04 & 920,58 & 70 & 6316 \\
\hline 8 & $\begin{array}{l}\text { Conta própria em casa sem carteira } \\
\text { (confecção, produção de alimentos, } \\
\text { manicure ou equivalente) }\end{array}$ & 75 & 901,29 & 503,30 & 55 & 2376 \\
\hline 10 & Pequeno produtor rural, criador & 38 & 859,21 & 701,37 & 70 & 4440 \\
\hline 11 & $\begin{array}{l}\text { Serviço doméstico com carteira assi- } \\
\text { nada }\end{array}$ & 20 & 826,4 & 324,16 & 300 & 1776 \\
\hline 12 & $\begin{array}{l}\text { Serviço doméstico sem carteira assi- } \\
\text { nada }\end{array}$ & 42 & 800,16 & 385,40 & 120 & 2076 \\
\hline & Total & 731 & 1307,27 & 1200,60 & 55 & 15760 \\
\hline
\end{tabular}

Fonte: Inaf (2015).

De fato, o nível médio de proficiência parece estar intimamente ligado aos salários. A Figura 1 (Apêndice A) resume o nível médio de proficiência por atividade desempenhada, 
seguindo a ordem de média salarial da Tabela 8 (tal ordenamento é seguido durante todo o estudo). Podemos observar que maiores níveis de proficiência estão relacionados com maiores médias salariais. Chama a atenção o fato de que nenhum grupo de ocupação possui uma média dentro da escala mais alta de proficiência. De acordo com o relatório do Inaf (LIMA; RIBEIRO; CATELLI, 2015), somente $8 \%$ da população entrevistada é proficiente na escala de alfabetismo. Em nossa amostra, apenas $9 \%$ alcançaram a escala de proficiência máxima.

E quanto aos scores socioemocionais? As Figuras 2, 3 e 4 (Apêndice A) apresentam o comportamento das medidas de Autogestão, Abertura ao Novo e Autoconceito por grupo de ocupação. É importante ressaltar que todos os scores foram normalizados a fim de observamos diferentes competências em uma mesma escala. Podemos notar que, em geral, as maiores médias se concentram nos grupos onde o salário é maior e as menores médias nos grupos onde o salário é menor. A fim de capturar uma medida de intensidade das três competências socioemocionais por grupo de ocupação, criamos uma nova medida construída pela média das três anteriores. A Figura 5 mostra o comportamento dessa nova medida por grupo de ocupação. Da mesma forma, podemos identificar uma relação positiva entre a medida criada e os grupos com maior média salarial.

Outra forma de verificar essa relação positiva é analisando a média dos scores por decil salarial. A Figura 6 (Apêndice A) ilustra tal análise para os três scores socioemocionais do Inaf e para a média dos três. A princípio, podemos perceber que existe uma ruptura bem evidente no $4^{\circ}$ decil de renda. Tal decil é justamente o ponto onde se encontram os indivíduos que ganham um salário mínimo ${ }^{1}$, o que faz com que o intervalo de renda em volta desse valor capture de forma grosseira a produtividade marginal do trabalho dos indivíduos, poluindo também a correlação com habilidades.

Apesar da ruptura do $4^{\circ}$ decil, percebemos uma correlação positiva entre renda e os scores socioemocionais. Outra forma de perceber essa relação positiva é mapeando também a distribuição dos scores socioemocionais. As Figuras 7, 8, 9 e 10 (Apêndice A) identificam os decis da distribuição na escala dos scores socioemocionais para cada competência. Em suma, ao se mover pelos decis de distribuição salarial, a trajetória das médias parecem partir do $3^{\circ}$ ou $4^{\circ}$ decil de distribuição socioemocional, chegando a ultrapassar o $6^{\circ}$ decil. Tal padrão de comportamento sugere mais uma vez que existe uma correlação positiva entre os scores socioemocionais e o salário.

Neste ponto, iniciamos a análise mais rigorosa de nosso estudo. Apresentamos a seguir os resultados obtidos pelo nosso modelo discutido na seção 5. A Tabela 9 resume os resultdos encontrados ao incluirmos os níveis latentes de habilidades cognitivas e não cognitivas na equação de salários. O modelo 1 contêm as estatísticas encontradas para

1 Em 2015, o salário mínimo equivalia a R\$ 788,00. Ver <https://www.tabeladeirrf.com.br/ tabela-do-salario-minimo.html> 
uma especificação sem o fator cognitivo e sem qualquer fator não cognitivo na equação de salário. No modelo 2 incluímos o fator cognitivo na especificação. O modelo 3 se refere à especificação apresentada na equação 5.1 onde incluímos um único fator não cognitivo (construído como a média dos 3 fatores socioemocionais do INAF) e o modelo 4 se refere à expansão da equação 5.1 para acomodar os três fatores não cognitivos presentes na base de dados.

Tabela 9 - Resultados dos modelos de salários

\begin{tabular}{lcccc}
\hline \hline & Modelo 1 & Modelo 2 & Modelo 3 & Modelo 4 \\
\hline Anos de Educação & $0,07^{* * *}$ & $0,06^{* * *}$ & $0,05^{* * *}$ & $0,05^{* * *}$ \\
Experiência & $0,02^{* *}$ & $0,02^{* *}$ & $0,02^{* *}$ & $0,02^{* *}$ \\
Experiência2 & $-0,00^{* *}$ & $-0,00^{*}$ & $-0,00^{*}$ & $-0,00^{* *}$ \\
Homem & $0,40^{* * *}$ & $0,39^{* * *}$ & $0,38^{* * *}$ & $0,38^{* * *}$ \\
Branco & $0,09^{*}$ & $0,09^{*}$ & $0,08^{*}$ & 0,08 \\
Norte & 0,01 & 0,02 & 0,04 & 0,04 \\
Sudeste & $0,26^{* * *}$ & $0,24^{* * *}$ & $0,24^{* * *}$ & $0,23^{* * *}$ \\
Sul & $0,31^{* * *}$ & $0,29^{* *}$ & $0,30^{* * *}$ & $0,30^{* *}$ \\
Centro Oeste & $0,37^{* * *}$ & $0,35^{* * *}$ & $0,37^{* * *}$ & $0,35^{* * *}$ \\
Proficiência INAF & & $0,06^{* *}$ & $0,06^{* *}$ & $0,06^{* *}$ \\
Média SEMS (normalizada) & & & $0,08^{* * *}$ & \\
Autogestão (normalizada) & & & & $-0,01$ \\
Abertura ao Novo (normalizada) & & & & $0,07^{* *}$ \\
Autoconceito (normalizada) & & & & $0,06^{* * *}$ \\
Constant & $5,58^{* * *}$ & $5,67^{* * *}$ & $5,73^{* * *}$ & $5,73^{* * *}$ \\
\hline N & 731 & 731 & 731 & 731 \\
r2 & 0,28 & 0,28 & 0,29 & 0,30 \\
\hline \hline
\end{tabular}

Fonte: Inaf 2015.

${ }^{*} p<0.10,{ }^{* *} p<0.05,{ }^{* * *} p<0.01$

Quatro descobertas valem ser destacadas. De início, damos ênfase à novidade da inclusão de fatores não cognitivos nas estimações (modelos 3 e 4), tendo em vista a negligência desse determinante na equação de salários. Em segundo lugar, nota-se o sinal positivo e a significância estatística do retorno associado ao único fator não cognitivo no modelo 3. A estatística $F$ encontrada para o teste de significância do parâmetro associado ao fator não cognitivo foi:

$$
\begin{gathered}
H_{0}: \gamma_{Y}^{N}=0 \\
F(1,14)=9,70 \\
\text { Prob }>F=0,0076 .
\end{gathered}
$$

Embora pareça um retorno de pequena magnitude (o ganho de um desvio padrão no fator não cognitivo se traduz em um aumento médio de $8 \%$ no salário), vale lembrar que anos de educação está sendo controlado na equação, ou seja, se acreditarmos que as competências socioemocionais interferem nos anos de educação dos indivíduos, pode existir um efeito de segunda ordem sobre salários via anos de educação. 
Uma terceira descoberta é a queda do retorno associado a anos de educação quando incluímos o fator cognitivo e o não cognitivo nas estimações, o que é coerente com a discussão em torno do viés de habilidade omitida. Por fim, ao considerarmos as três medidas socioemocionais disponíveis na estimação, encontramos pistas de que Abertura ao Novo $(F(1,14)=6,33$ e Prob $>F=0,0247)$ e Autoconceito $(F(1,14)=14,80$ e $\operatorname{Prob}>F=0,0018$ ) parecem ser mais importantes que autoconceito para explicar salários, o que não parece ser rapidamente intuitivo, merecendo mais investigações futuras. Entretanto, o teste de significância conjunta dos três coeficientes reafirma a existência do retorno relacionado às competências socioemocionais:

$$
\begin{gathered}
H_{0}: \gamma_{Y}^{N 1}=\gamma_{Y}^{N 2}=\gamma_{Y}^{N 3}=0 \\
F(3,14)=8,08 \\
\text { Prob }>F=0,0023
\end{gathered}
$$

Respondendo a primeira questão proposta por esse estudo, tais evidências sugerem que, de fato, existe um retorno associado às competências socioemocionais para o mercado de trabalho brasileiro. Além disso, encontramos sinais de que o mercado premia de forma distinta diferentes competências. Para verificar se tal retorno também difere entre os grupos de ocupação identificados (segunda questão proposta por esse estudo), incluímos interações em nosso modelo entre o score socioemocional e dummies de grupos de ocupação, conforme descrito na equação 5.3. A Tabela 10 resume os principais resultados desse exercício, apresentando os coeficientes encontrados para os fatores socioemocionais e suas interações com as dummies de grupos de ocupação.

Como se pode notar, encontramos valores positivos e significativos apenas para alguns grupos de ocupação, são eles: grupo 2 (função de coordenação, supervisão, técnico especialista, assessor ou equivalente, professor, médico, advogado), grupo 6 (Especialista, prestador de serviços de nível superior) e grupo 9 (Conta própria fora de casa sem carteira), sugerindo assim que as competências socioemocionais são valoradas de forma distinta entre os grupos de ocupação.

Sobre os diversos valores não significativos encontrados, pode-se argumentar que por conta da agregação de várias ocupações que envolvem diferentes tarefas, e por consequência, fundem profissionais com diferentes competências, os resultados reflitam na verdade o efeito líquido de tal agrupamento. Como os dados não nos permitem identificar a ocupação de cada indivíduo, somos limitados a analisar somente a diferença entre essas classificações. 
Tabela 10 - Resultados do modelo de salários - grupos de ocupação

\begin{tabular}{lcccc}
\hline \hline & Autogestão & Abertura & Autoconceito & Média SEMS \\
\hline score_sems & $-0,02$ & $-0,07$ & 0,01 & 0,01 \\
$\delta_{1}$ & 0,16 & 0,12 & 0,21 & 0,11 \\
$\delta_{2}$ & $0,17^{*}$ & $0,20^{* *}$ & 0,13 & 0,11 \\
$\delta_{3}$ & 0,06 & 0,08 & 0,02 & 0,04 \\
$\delta_{4}$ & 0,17 & 0,00 & 0,21 & 0,19 \\
$\delta_{5}$ & $-0,01$ & 0,08 & $-0,01$ & $-0,12$ \\
$\delta_{6}$ & 0,37 & 0,27 & 0,06 & $0,49^{*}$ \\
$\delta_{7}$ & 0,03 & 0,07 & $-0,03$ & 0,02 \\
$\delta_{8}$ & 0,12 & 0,13 & 0,07 & 0,08 \\
$\delta_{9}$ & $0,22^{* *}$ & $0,23^{* *}$ & $0,18^{*}$ & 0,10 \\
$\delta_{10}$ & 0,18 & 0,18 & 0,12 & 0,10 \\
$\delta_{11}$ & 0,08 & 0,18 & $-0,00$ & 0,01 \\
\hline $\mathrm{N}$ & 731 & 731 & 731 & 731 \\
$\mathrm{r} 2$ & 0,35 & 0,34 & 0,34 & 0,34 \\
\hline \hline
\end{tabular}

Fonte: Inaf 2015.

${ }^{*} p<0.10,{ }^{* *} p<0.05,{ }^{* * *} p<0.01$

1 - Função de direção, gerência.

2 - Função de coordenação, supervisão, técnico especialista, assessor ou equivalente, professor, médico, advogado.

3 - Função operacional, não especialista, assistente, operador ou equivalente. 4 - Empresário, grande proprietário rural, criador, industrial, empregador, investidor.

5 - Microempresário.

6 - Especialista, prestador de serviços de nível superior (advogado, médico, arquiteto, engenheiro, contador, dentista, etc).

7 - Especialista, prestador de serviços de nível técnico (representante comercial, vendedor, mecânico, instalador, etc).

8 - Conta própria em casa sem carteira (confecção, produção de alimentos, manicure ou equivalente).

9 - Conta própria fora de casa sem carteira (camelô, ambulante, biscate, bico, boia fria ou equivalente).

10 - Pequeno produtor rural, criador.

11 - Serviço doméstico com carteira assinada.

12 - Serviço doméstico sem carteira assinada. (categoria omitida) 


\section{Considerações Finais}

Motivados pelas transformações advindas dos rápidos avanços da tecnologia e desenvolvimentos em diversos campos da ciência, nosso estudo se propõe a investigar o papel das chamadas competências socioemocionais ou "soft skills" no mercado de trabalho brasileiro, uma vez que diversas evidências internacionais tem apontado para sua crescente valorização no mundo do trabalho. Buscamos discutir a respeito da existência de um retorno associado às habilidades socioemocionais no mercado nacional e da heterogeneidade de valorização dessas competências entre diferentes grupos de ocupação.

Utilizando dados do Inaf de 2015, encontramos evidências de que o mercado de trabalho brasileiro têm valorizado as competências socioemocionais: existe uma relação positiva entre essas competências e o salário, indicando que existe ganho salarial para indivíduos que possuem fatores não cognitivos mais desenvolvidos. Essa valorização das competências socioemocionais é diferente entre grupos de ocupação, sugerindo que essa apreciação não é uniforme no mercado, depende da natureza da atividade realizada.

Acreditamos que o conhecimento gerado nesse estudo possa integrar a literatura sobre o tema e incentivar novos estudos sobre a relação entre as competências socioemocionais e o mercado de trabalho. Além disso, esperamos que os resultados apresentados ajudem a direcionar políticas públicas e programas de desenvolvimento de habilidades para o mercado de trabalho, a fim de gerir melhor o impacto transformador da Quarta Revolução Industrial no emprego, nas competências e na educação. 


\section{Referências}

ACEMOGLU, D.; AUTOR, D. Skills, tasks and technologies: Implications for employment and earnings. Handbook of labor economics, Elsevier, v. 4, p. 1043-1171, 2011. Citado 2 vezes nas páginas 14 e 15.

ADERMON, A.; GUSTAVSSON, M. Job polarization and task-biased technological change: Evidence from sweden, 1975-2005. The Scandinavian Journal of Economics, Wiley Online Library, v. 117, n. 3, p. 878-917, 2015. Citado na página 14.

ALMLund, M. et al. Personality psychology and economics. [S.l.], 2011. Citado na página 21.

AUTOR, D.; KATZ, L. F.; KEARNEY, M. S. The polarization of the US labor market. [S.1.], 2006. Citado na página 14.

AUTOR, D. et al. Polanyi's paradox and the shape of employment growth. [S.l.]: National Bureau of Economic Research Cambridge, MA, 2014. v. 20485. Citado na página 15.

AUTOR, D. H.; DORN, D. The growth of low-skill service jobs and the polarization of the us labor market. The American Economic Review, American Economic Association, v. 103, n. 5, p. 1553-1597, 2013. Citado na página 14.

AUTOR, D. H.; KATZ, L. F.; KEARNEY, M. S. Trends in us wage inequality: Revising the revisionists. The Review of economics and statistics, MIT Press, v. 90, n. 2, p. 300-323, 2008. Citado na página 14.

AUTOR, D. H.; LEVY, F.; MURNANE, R. J. The skill content of recent technological change: An empirical exploration. The Quarterly journal of economics, MIT Press, v. 118, n. 4, p. 1279-1333, 2003. Citado 2 vezes nas páginas 14 e 21.

BALCAR, J. Soft skills and their wage returns: Overview of empirical literature. Review of Economic Perspectives, v. 14, n. 1, p. 3-15, 2014. Citado 2 vezes nas páginas 16 e 21.

BARON-COHEN, S. Theory of mind and autism: A fifteen year review. Understanding other minds: Perspectives from developmental cognitive neuroscience, v. 2, p. 3-20, 2000. Citado na página 16.

BEAUDRY, P.; GREEN, D. A.; SAND, B. M. The great reversal in the demand for skill and cognitive tasks. Journal of Labor Economics, University of Chicago Press Chicago, IL, v. 34, n. S1, p. S199-S247, 2016. Citado na página 15.

BECKER, G. S. Investment in human capital: A theoretical analysis. Journal of political economy, The University of Chicago Press, v. 70, n. 5, Part 2, p. 9-49, 1962. Citado na página 13.

BECKER, G. S. Human capital revisited. In: Human Capital: A Theoretical and Empirical Analysis with Special Reference to Education (3rd Edition). [S.1.]: The University of Chicago Press, 1994. p. 15-28. Citado 2 vezes nas páginas 13 e 32. 
BEKMAN, E.; BOUND, J.; MACHIN, S. Implications of skill-biased technological change: international evidence. The quarterly journal of economics, MIT Press, v. 113, n. 4, p. 1245-1279, 1998. Citado na página 13.

BEN-PORATH, Y. The production of human capital and the life cycle of earnings. Journal of political economy, The University of Chicago Press, v. 75, n. 4, Part 1, p. 352-365, 1967. Citado na página 13.

BENDASSOLLI, P. F.; MALVEZZI, S. Desempenho no trabalho: definições, modelos teóricos e desafios à gestão. O trabalho e as organizações: atuações a partir da psicologia. Porto Alegre: Artmed, p. 53-84, 2013. Citado na página 23.

BLOEM, J. et al. The fourth industrial revolution. Things Tighten, 2014. Citado na página 18.

BOLSONI-SILVA, A. T. et al. A área das habilidades sociais no brasil: Uma análise dos estudos publicados em periódicos. Estudos sobre habilidades sociais e relacionamento interpessoal, Casa do Psicólogo São Paulo, p. 17-45, 2006. Citado na página 23.

BOUND, J.; JOHNSON, G. E. Changes in the Structure of Wages during the 1980's: An Evaluation of Alternative Explanations. [S.l.], 1989. Citado 2 vezes nas páginas 14 e 15.

BRUNELLO, G.; SCHLOTTER, M. Non-cognitive skills and personality traits: Labour market relevance and their development in education \& training systems. 2011. Citado 2 vezes nas páginas 21 e 22 .

BRYNJOLFSSON, E.; MCAFEE, A. Race against the machine: How the digital revolution is accelerating innovation, driving productivity, and irreversibly transforming employment and the economy. [S.1.]: Brynjolfsson and McAfee, 2012. Citado 2 vezes nas páginas 15 e 18.

BUSSO, M. et al. Desconectados: habilidades, educación y empleo en América Latina. [S.l.]: BID, 2012. Citado na página 22.

CAMERER, C.; LOEWENSTEIN, G.; PRELEC, D. Neuroeconomics: How neuroscience can inform economics. Journal of Economic Literature, v. 43, p. 9-64, 2005. Citado na página 16.

CARMELI, A.; JOSMAN, Z. E. The relationship among emotional intelligence, task performance, and organizational citizenship behaviors. Human performance, Taylor \& Francis, v. 19, n. 4, p. 403-419, 2006. Citado na página 21.

CASTEX, G.; DECHTER, E. K. The changing roles of education and ability in wage determination. Journal of Labor Economics, University of Chicago Press Chicago, IL, v. 32, n. 4, p. 685-710, 2014. Citado na página 15.

CRÉPON, B.; BERG, G. J. Van den. Active labor market policies. Annual Review of Economics, Annual Reviews, v. 8, p. 521-546, 2016. Citado 2 vezes nas páginas 21 e 22.

CUNHA, F.; HECKMAN, J. J.; SCHENNACH, S. M. Estimating the technology of cognitive and noncognitive skill formation. Econometrica, Wiley Online Library, v. 78, n. 3, p. 883-931, 2010. Citado na página 21. 
CUNNINGHAM, W.; VILLASEÑOR, P. Employer voices, employer demands, and implications for public skills development policy. [S.l.]: The World Bank, 2014. Citado 2 vezes nas páginas 19 e 22.

DAVIS, S. J. Cross-country patterns of change in relative wages. NBER macroeconomics annual, MIT Press, v. 7, p. 239-292, 1992. Citado na página 13.

DEMING, D. J. The growing importance of social skills in the labor market. [S.1.], 2015. Citado 5 vezes nas páginas 14, 15, 16, 21 e 23.

DOUGLAS, P. H. et al. Real wages in the united states, 1890-1926. Houghton Mifflin, Boston, MA, Houghton Mifflin Co., 1930. Citado na página 12.

EDISON, T. A. Genius is one percent inspiration and ninety-nine percent perspiration. Quoted in Harper's Monthly Magazine, 1932. Citado na página 6.

FREEMAN, R. B.; KATZ, L. F. lRising Wage Inequality: The United States vs. Other Advanced Countries, min Richard B. [S.1.]: Freeman, ed., Working Under Different Rules. New York: Russell Sage Foundation, 1994. Citado na página 13.

FREY, C. B.; OSBORNE, M. A. The future of employment: how susceptible are jobs to computerisation? Technological Forecasting and Social Change, Elsevier, v. 114, p. 254-280, 2017. Citado 2 vezes nas páginas 15 e 18.

GONDIM, S. M. G.; MORAIS, F. A. d.; BRAnTES, C. d. A. A. Competências socioemocionais: fator-chave no desenvolvimento de competências para o trabalho. Revista Psicologia Organizações e Trabalho, Associação Brasileira de Psicologia Organizacional e do Trabalho (SBPOT), v. 14, n. 4, p. 394-406, 2014. Citado na página 23.

GOOS, M.; MANNING, A. Lousy and lovely jobs: The rising polarization of work in britain. The review of economics and statistics, MIT Press, v. 89, n. 1, p. 118-133, 2007. Citado na página 14.

GOOS, M.; MANNING, A.; SALOMONS, A. Explaining job polarization: Routine-biased technological change and offshoring. The American Economic Review, American Economic Association, v. 104, n. 8, p. 2509-2526, 2014. Citado na página 14.

GOTTSCHALK, P.; SMEEDING, T. M. Cross-national comparisons of earnings and income inequality. Journal of economic literature, JSTOR, v. 35, n. 2, p. 633-687, 1997. Citado na página 13.

GROGGER, J.; EIDE, E. Changes in college skills and the rise in the college wage premium. Journal of Human Resources, JSTOR, p. 280-310, 1995. Citado 2 vezes nas páginas 14 e 15.

GUERRA, N.; MODECKI, K.; CUNNINGHAM, W. Developing social-emotional skills for the labor market: The PRACTICE model. [S.l.]: The World Bank, 2014. Citado na página 22.

HASKEL, J. E.; SLAUGHTER, M. J. Does the sector bias of skill-biased technical change explain changing wage inequality? [S.l.], 1998. Citado na página 13. 
HAYS. Regional dynamics of the global labour market - skills in demand and tomorrow's workforce. Hays Global Skills Index, 2017. Disponível em: $<$ https://www.hays.com.br/skills-index/index.htm>. Citado na página 20.

HECKMAN, J.; VYTLACIL, E. Identifying the role of cognitive ability in explaining the level of and change in the return to schooling. Review of Economics and Statistics, MIT Press, v. 83, n. 1, p. 1-12, 2001. Citado 2 vezes nas páginas 14 e 15.

HECKMAN, J. J. Lessons from the bell curve. Journal of Political Economy, The University of Chicago Press, v. 103, n. 5, p. 1091-1120, 1995. Citado na página 33.

HECKMAN, J. J.; KAUTZ, T. Hard evidence on soft skills. Labour economics, Elsevier, v. 19, n. 4, p. 451-464, 2012. Citado 3 vezes nas páginas 19, 21 e 32.

HECKMAN, J. J.; RUBINSTEIN, Y. The importance of noncognitive skills: Lessons from the ged testing program. The American Economic Review, JSTOR, v. 91, n. 2, p. 145-149, 2001. Citado 2 vezes nas páginas 21 e 32.

HECKMAN, J. J.; STIXRUD, J.; URZUA, S. The effects of cognitive and noncognitive abilities on labor market outcomes and social behavior. Journal of Labor economics, The University of Chicago Press, v. 24, n. 3, p. 411-482, 2006. Citado 2 vezes nas páginas 21 e 32 .

JOHN, O. P.; DONAHUE, E. M.; KENTLE, R. L. The big five inventory-versions $4 a$ and 54. [S.1.]: Berkeley, CA: University of California, Berkeley, Institute of Personality and Social Research, 1991. Citado na página 32.

JUDGE, T. A. et al. The core self-evaluations scale: Development of a measure. Personnel psychology, Wiley Online Library, v. 56, n. 2, p. 303-331, 2003. Citado 2 vezes nas páginas 28 e 29.

JUHN, C.; MURPHY, K. M.; PIERCE, B. Wage inequality and the rise in returns to skill. Journal of political Economy, The University of Chicago Press, v. 101, n. 3, p. 410-442, 1993. Citado 2 vezes nas páginas 14 e 15.

KARABARBOUNIS, L.; NEIMAN, B. The global decline of the labor share. The Quarterly Journal of Economics, Oxford University Press, v. 129, n. 1, p. 61-103, 2013. Citado na página 15.

KATZ, L. et al. Active labor market policies to expand employment and opportunity. Reducing unemployment: Current issues and policy options, p. 239-290, 1994. Citado na página 13.

KATZ, L. F.; AUTOR, D. H. Changes in the wage structure and earnings inequality. Handbook of labor economics, Elsevier, v. 3, p. 1463-1555, 1999. Citado 2 vezes nas páginas 13 e 14 .

KATZ, L. F.; MURPHY, K. M. Changes in relative wages, 1963-1987: supply and demand factors. The quarterly journal of economics, MIT Press, v. 107, n. 1, p. 35-78, 1992. Citado 2 vezes nas páginas 14 e 15.

LEE, W. The conceptual framework of the 21st century competencies. Keynote paper presented at the Education and 21st Century Competencies, hosted by the Ministry of Education, p. 22-24, 2013. Citado na página 19. 
LIMA, A.; RIBEIRO, V.; CATELLI, R. Alfabetismo no mundo do trabalho. INDICADOR DE ALFABETISMO FUNCIONAL - INAF, 2015. Disponível em: $<$ http://ipm.org.br/relatorios>. Citado 2 vezes nas páginas 27 e 37.

LINDQVIST, E.; VESTMAN, R. The labor market returns to cognitive and noncognitive ability: Evidence from the swedish enlistment. American Economic Journal: Applied Economics, American Economic Association, v. 3, n. 1, p. 101-128, 2011. Citado na página 21.

LU, Q. The End of Polarization? Technological Change and Employment in the US Labor Market. [S.l.], 2015. Citado na página 15.

MICHAELS, G.; NATRAJ, A.; REENEN, J. V. Has ict polarized skill demand? evidence from eleven countries over twenty-five years. Review of Economics and Statistics, MIT Press, v. 96, n. 1, p. 60-77, 2014. Citado na página 14.

MINCER, J. Schooling, experience, and earnings. human behavior \& social institutions no. 2. ERIC, 1974. Citado na página 13.

MONTGOMERY, J. D. Values in Education: Social Capital Formation in Asia and the Pacific. [S.l.]: ERIC, 1997. Citado na página 19.

MURNANE, R. J.; WILLETT, J. B.; LEVY, F. The growing importance of cognitive skills in wage determination. [S.l.], 1995. Citado 2 vezes nas páginas 14 e 15.

NICKELL, S.; BELL, B. The collapse in demand for the unskilled and unemployment across the oecd. Oxford review of economic policy, JSTOR, v. 11, n. 1, p. 40-62, 1995. Citado na página 13.

OBER, H. Occupational wage differentials, 1907-1947. Monthly Lab. Rev., HeinOnline, v. 67, p. 127,1948 . Citado na página 12.

O'BOYLE, E. H. et al. The relation between emotional intelligence and job performance: A meta-analysis. Journal of Organizational Behavior, Wiley Online Library, v. 32, n. 5, p. 788-818, 2011. Citado na página 21.

OECD. OECD Employment Outlook: June 1993. [S.1.]: Organisation for Economic Co-operation and Development, 1993. Citado na página 13.

OECD. OECD Employment Outlook: June 1996. [S.l.]: Organisation for Economic Co-operation and Development, 1996. Citado na página 13.

OECD. OECD Employment Outlook: June 1997. [S.l.]: Organisation for Economic Co-operation and Development, 1997. Citado na página 13.

O'CONNOR, M. C.; PAUNONEN, S. V. Big five personality predictors of post-secondary academic performance. Personality and Individual differences, Elsevier, v. 43, n. 5, p. 971-990, 2007. Citado na página 21.

PETERS, M. A. Technological unemployment: Educating for the fourth industrial revolution. [S.1.]: Taylor \& Francis, 2017. Citado na página 18.

POROPAT, A. E. A meta-analysis of the five-factor model of personality and academic performance. Psychological bulletin, American Psychological Association, v. 135, n. 2, p. 322, 2009. Citado na página 21. 
PREMACK, D.; WOODRUFF, G. Does the chimpanzee have a theory of mind? Behavioral and brain sciences, Cambridge University Press, v. 1, n. 4, p. 515-526, 1978. Citado na página 16.

PRIMI, R. et al. Development of an inventory assessing social and emotional skills in brazilian youth. European Journal of Psychological Assessment, Hogrefe Publishing, 2016. Citado 3 vezes nas páginas 21, 28 e 29.

RICHARD, B. F.; KATZ, L. F. Differences and Changes in Wage Structures. [S.1.]: Chicago: University of Chicago Press and NBER, 1995. Citado na página 13.

SANTOS, D.; PRIMI, R. Desenvolvimento socioemocional e aprendizado escolar: uma proposta de mensuração para apoiar políticas públicas. Relatório sobre resultados preliminares do projeto de medição de competências socioemocionais no Rio de Janeiro. São Paulo: OCDE, SEEDUC, Instituto Ayrton Senna, 2014. Citado 3 vezes nas páginas 21,28 e 32.

SCALE, P. Payscale and future workplace release 2016 workforce-skills preparedness report. Pay Scale Inc., Seattle, WA, 2016. Citado na página 20.

SCHANZENBACH, D. W. et al. Seven facts on noncognitive skills from education to the labor market. Hamilton Project, Washington, District of Columbia, 2016. Citado na página 21.

SCHWAB, K. The fourth industrial revolution. [S.l.]: Crown Business, 2017. Citado na página 18.

SCHWAB, K.; SAMANS, R. The future of jobs: employment, skills and workforce strategy for the fourth industrial revolution. In: WORLD ECONOMIC FORUM, GENEVA, SWITZERLAND. [S.l.], 2016. Citado 2 vezes nas páginas 18 e 19.

SLICHTER, S. H. Notes on the structure of wages. The Review of Economics and Statistics, JSTOR, p. 80-91, 1950. Citado na página 12.

SMITH, A. A riqueza das nações. [S.l.]: Nova Fronteira, 2017. Nenhuma citação no texto.

SUSSKIND, R.; SUSSKIND, D. The future of the professions: How technology will transform the work of human experts. [S.l.]: Oxford University Press, USA, 2015. Citado na página 18.

TABER, C. R. The rising college premium in the eighties: Return to college or return to unobserved ability? The Review of Economic Studies, Wiley-Blackwell, v. 68, n. 3, p. 665-691, 2001. Citado 2 vezes nas páginas 14 e 15.

TINBERGEN, J. Substitution of graduate by other labour. Kyklos, Wiley Online Library, v. 27, n. 2, p. 217-226, 1974. Citado na página 13.

TINBERGEN, J. Income differences: recent research. [S.l.: s.n.], 1975. Citado na página 13.

WEINBERGER, C. J. The increasing complementarity between cognitive and social skills. Review of Economics and Statistics, MIT Press, v. 96, n. 4, p. 849-861, 2014. Citado 2 vezes nas páginas 16 e 21. 
WILLIS, R. J. Wage determinants: A survey and reinterpretation of human capital earnings functions. Handbook of labor economics, Elsevier, v. 1, p. 525-602, 1986. Citado na página 13.

WOOD, A. North-south trade. Employment and Inequality: Changing fortunes in a skill-driven, 1994. Citado na página 13.

ZINS, J. E. et al. The scientific base linking social and emotional learning to school success. Building academic success on social and emotional learning: What does the research say, p. 3-22, 2004. Citado na página 21. 
Apêndices 


\section{APÊNDICE A - Figuras}

Figura 1 - Proficiencia em Alfabetismo por Grupo de Ocupação

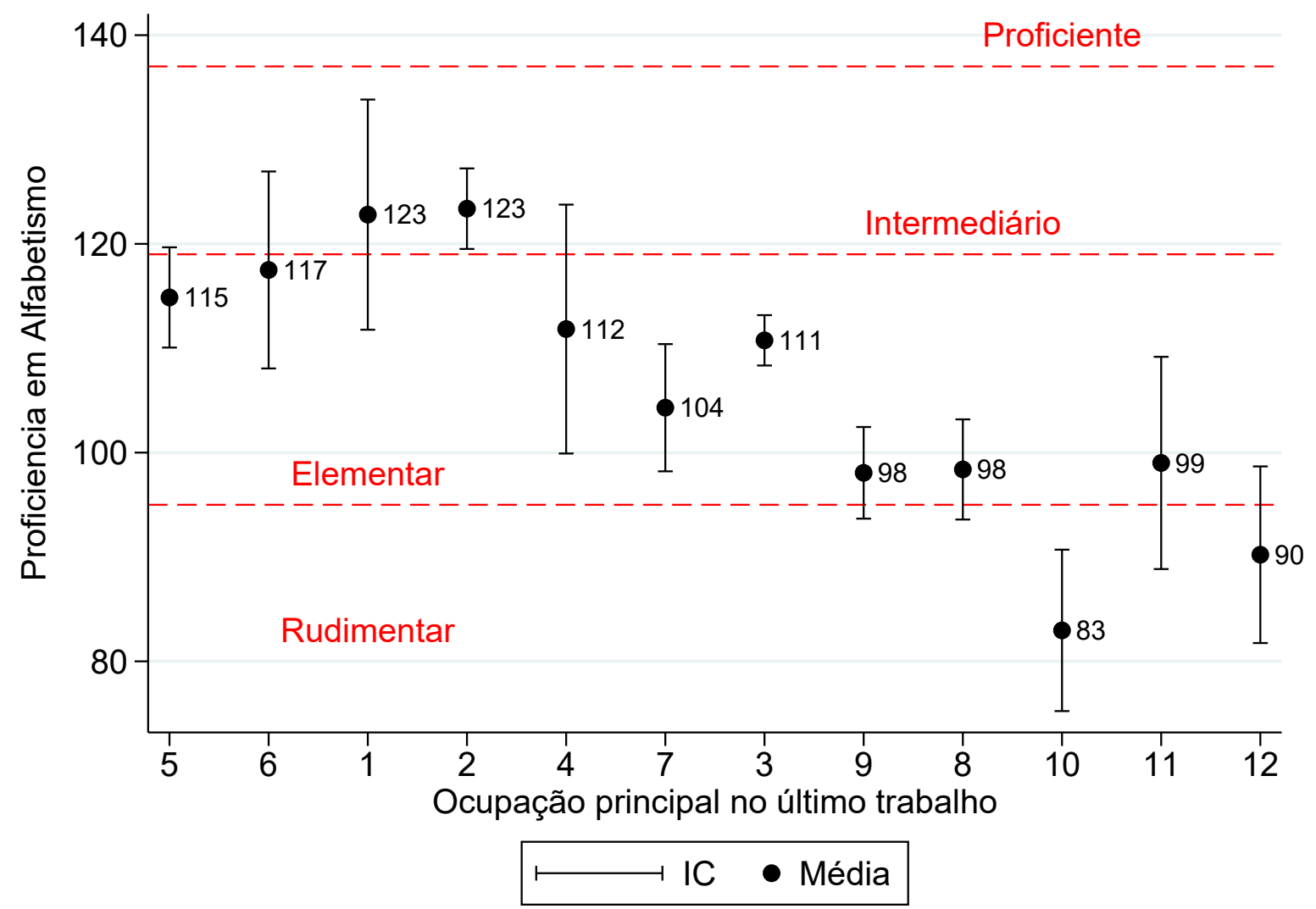

Notas:

1 - Função de direção, gerência.

2 - Função de coordenação, supervisão, técnico especialista, assessor ou equivalente, professor, médico, advogado.

3 - Função operacional, não especialista, assistente, operador ou equivalente.

4 - Empresário, grande proprietário rural, criador, industrial, empregador, investidor.

5 - Microempresário.

6 - Especialista, prestador de serviços de nível superior (advogado, médico, arquiteto, engenheiro, contador, dentista).

7 - Especialista, prestador de serviços de nível técnico (representante comercial, vendedor, mecânico, instalador, atleta).

8 - Conta própria em casa sem carteira (confecção, produção de alimentos, manicure ou equivalente).

9 - Conta própria fora de casa sem carteira (camelô, ambulante, biscate, bico, boia fria ou equivalente).

10 - Pequeno produtor rural, criador.

11 - Serviço doméstico com carteira assinada.

12 - Serviço doméstico sem carteira assinada.

Fonte: Inaf 2015.

As escalas de proficiência do Inaf 2015 podem ser lidas da seguinte maneira:

- Analfabeto $(0<x \leq 50) \rightarrow$ Corresponde à condição dos que não conseguem realizar tarefas simples que envolvem a leitura de palavras e frases, ainda que uma 
parcela destes consiga ler números familiares (números de telefone, preços, etc.).

- Rudimentar $(50<x \leq 95) \rightarrow$ Localiza uma ou mais informações explícitas, expressas de forma literal em textos muito simples; Compara, lê e escreve números familiares (horários, preços, cédulas/moedas; Resolve problemas simples do cotidiano envolvendo operações matemáticas elementares telefone); Reconhece sinais de pontuação (vírgula, exclamação, interrogação, etc.) pelo nome ou função.

- Elementar $(95<x \leq 119) \rightarrow$ Seleciona uma ou mais unidades de informação, observando certas condições, em textos diversos de extensão média reali-zando pequenas inferências; Resolve problemas envolvendo operações básicas com nú-meros da ordem do milhar, que exigem certo grau de pla-nejamento e controle; Compara ou relaciona informações numéricas ou textuais expressas em gráficos ou tabelas simples, envolvendo situações de contexto cotidiano doméstico ou social; Reconhece significado de representação gráfica de direção e/ou sentido de uma grandeza.

- Intermediário $(119<x \leq 137) \rightarrow$ Localiza informação expressa de forma literal em textos diversos (jornalístico e/ou científico) realizando pequenas inferências; Resolve problemas envolvendo operações matemáticas mais complexas (cálculo de porcentagens e proporções) da ordem dos milhões, que exigem critérios de seleção de informações, elaboração e controle em situações diversas; Interpreta e elabora síntese de textos diversos (narrativos, jornalísticos, científicos), relacionando regras com casos particulares a partir do reconhecimento de evidências e argumentos e confrontando a moral da história com sua própria opinião ou senso comum; Reconhece o efeito de sentido ou estético de escolhas lexicais ou sintáticas, de figuras de linguagem ou sinais de pontuação.

- Proficiente $(x>137) \rightarrow$ Elabora textos de maior complexidade (mensagem, descrição, exposição ou argumentação) com base em elementos de um contexto dado e opina sobre o posicionamento ou estilo do autor do texto; Interpreta tabelas e gráficos envolvendo mais de duas variáveis, compreendendo elementos que caracterizam certos modos de representação de informação quantitativa (escolha do intervalo, escala, sistema de medidas ou padrões de comparação) reconhecendo efeitos de sentido (ênfases, distorções, tendências, projeções); Resolve situações-problema relativas a tarefas de contextos diversos, que envolvem diversas etapas de planejamento, controle e elaboração, que exigem retomada de resultados parciais e o uso de inferências. 
Figura 2 - Score Socioemocional por Grupo de Ocupação (Inaf 2015) - Autogestão

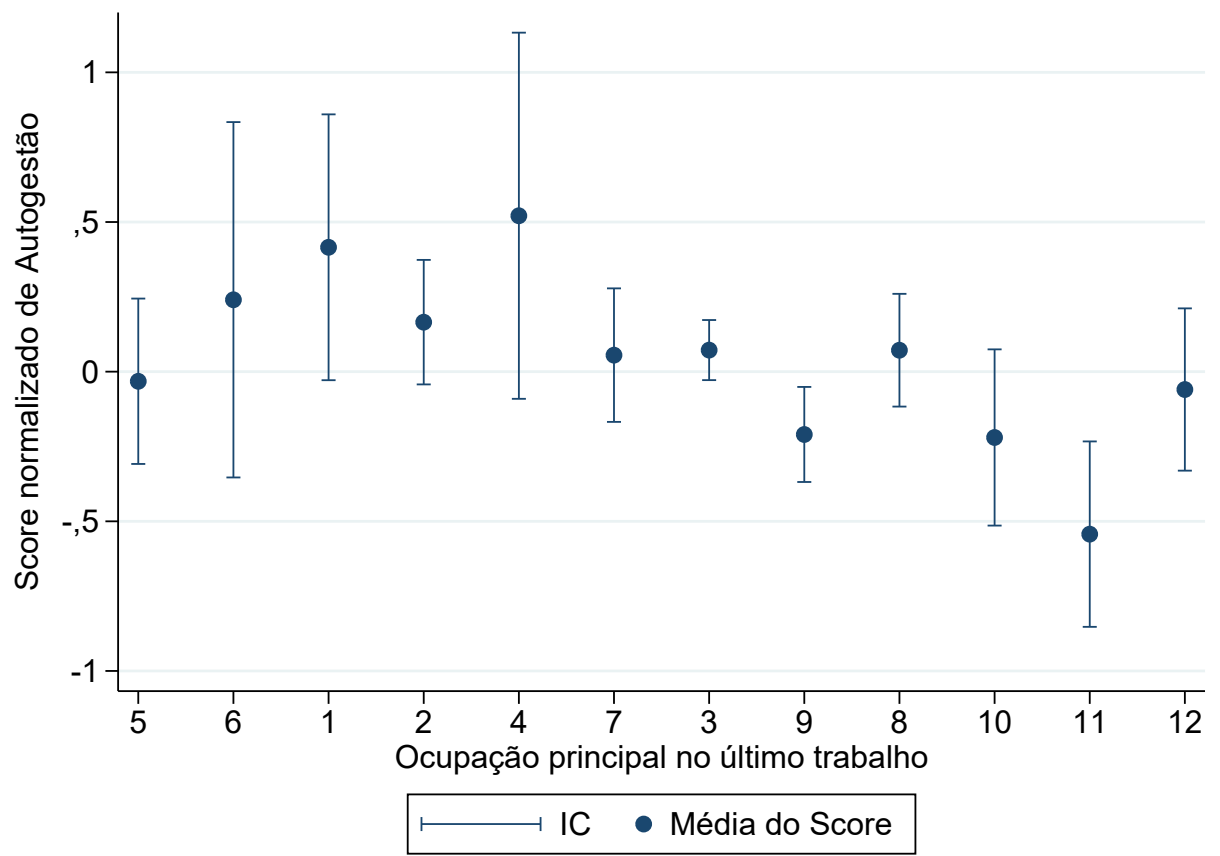

Notas:

1 - Função de direção, gerência.

2 - Função de coordenação, supervisão, técnico especialista, assessor ou equivalente, professor, médico, advogado.

3 - Função operacional, não especialista, assistente, operador ou equivalente.

4 - Empresário, grande proprietário rural, criador, industrial, empregador, investidor.

5 - Microempresário.

6 - Especialista, prestador de serviços de nível superior (advogado, médico, arquiteto, engenheiro, contador, dentista).

7 - Especialista, prestador de serviços de nível técnico (representante comercial, vendedor, mecânico, instalador, atleta).

8 - Conta própria em casa sem carteira (confecção, produção de alimentos, manicure ou equivalente).

9 - Conta própria fora de casa sem carteira (camelô, ambulante, biscate, bico, boia fria ou equivalente).

10 - Pequeno produtor rural, criador.

11 - Serviço doméstico com carteira assinada.

12 - Serviço doméstico sem carteira assinada.

Fonte: Inaf 2015. 
Figura 3 - Score Socioemocional por Grupo de Ocupação (Inaf 2015) - Abertura ao Novo

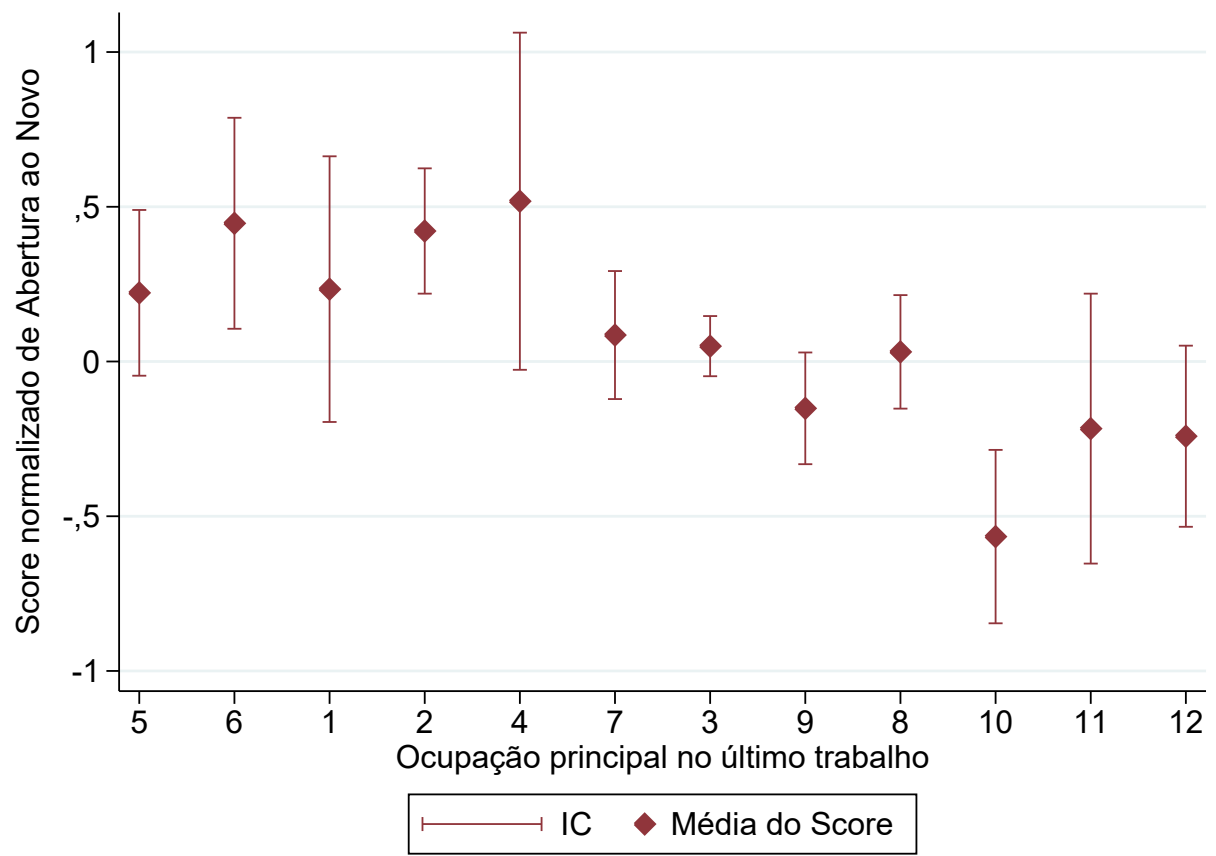

Notas:

1 - Função de direção, gerência.

2 - Função de coordenação, supervisão, técnico especialista, assessor ou equivalente, professor, médico, advogado.

3 - Função operacional, não especialista, assistente, operador ou equivalente.

4 - Empresário, grande proprietário rural, criador, industrial, empregador, investidor.

5 - Microempresário.

6 - Especialista, prestador de serviços de nível superior (advogado, médico, arquiteto, engenheiro, contador, dentista).

7 - Especialista, prestador de serviços de nível técnico (representante comercial, vendedor, mecânico, instalador, atleta).

8 - Conta própria em casa sem carteira (confecção, produção de alimentos, manicure ou equivalente).

9 - Conta própria fora de casa sem carteira (camelô, ambulante, biscate, bico, boia fria ou equivalente).

10 - Pequeno produtor rural, criador.

11 - Serviço doméstico com carteira assinada.

12 - Serviço doméstico sem carteira assinada.

Fonte: Inaf 2015. 
Figura 4 - Score Socioemocional por Grupo de Ocupação (Inaf 2015) - Autoconceito

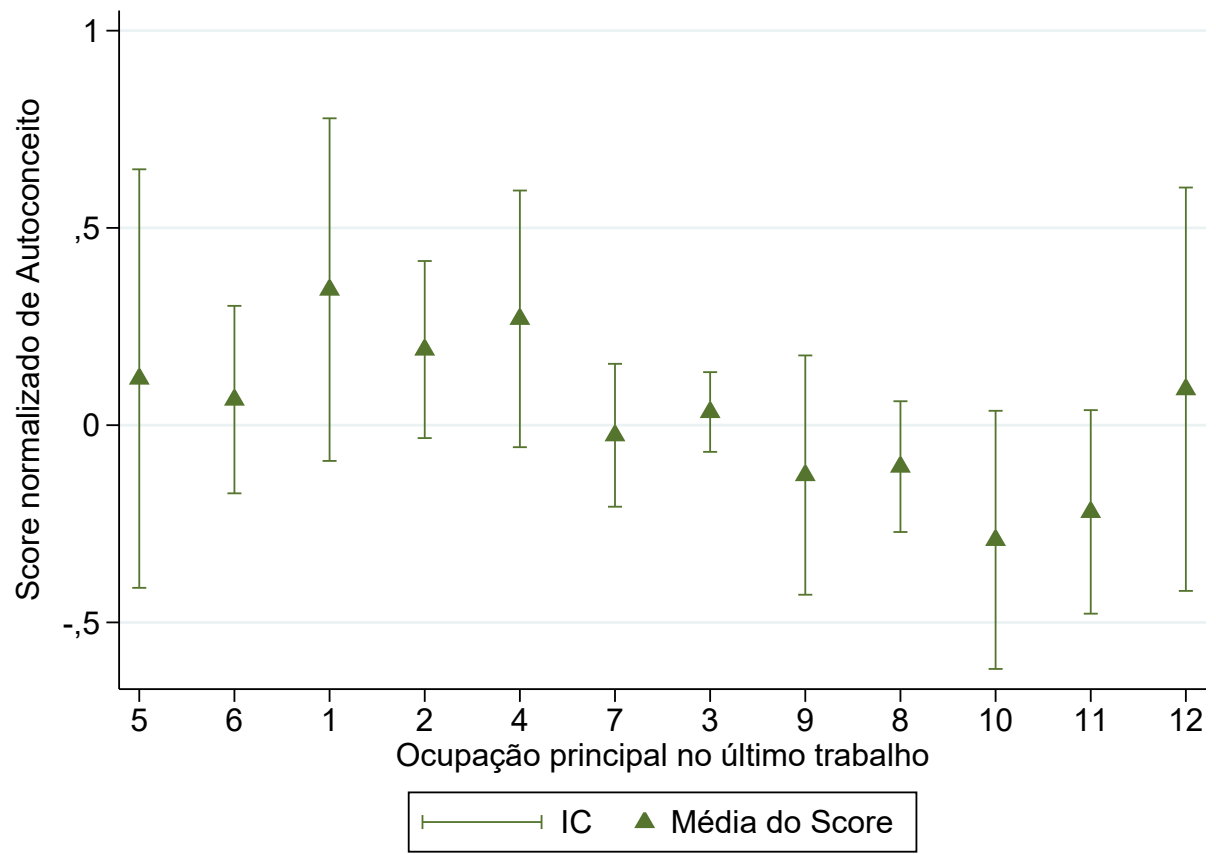

Notas:

1 - Função de direção, gerência

2 - Função de coordenação, supervisão, técnico especialista, assessor ou equivalente, professor, médico, advogado.

3 - Função operacional, não especialista, assistente, operador ou equivalente.

4 - Empresário, grande proprietário rural, criador, industrial, empregador, investidor.

5 - Microempresário.

6 - Especialista, prestador de serviços de nível superior (advogado, médico, arquiteto, engenheiro, contador, dentista).

7 - Especialista, prestador de serviços de nível técnico (representante comercial, vendedor, mecânico, instalador, atleta).

8 - Conta própria em casa sem carteira (confecção, produção de alimentos, manicure ou equivalente).

9 - Conta própria fora de casa sem carteira (camelô, ambulante, biscate, bico, boia fria ou equivalente).

10 - Pequeno produtor rural, criador.

11 - Serviço doméstico com carteira assinada.

12 - Serviço doméstico sem carteira assinada.

Fonte: Inaf 2015. 
Figura 5 - Score Socioemocional por Grupo de Ocupação (Inaf 2015) - Média SEMS

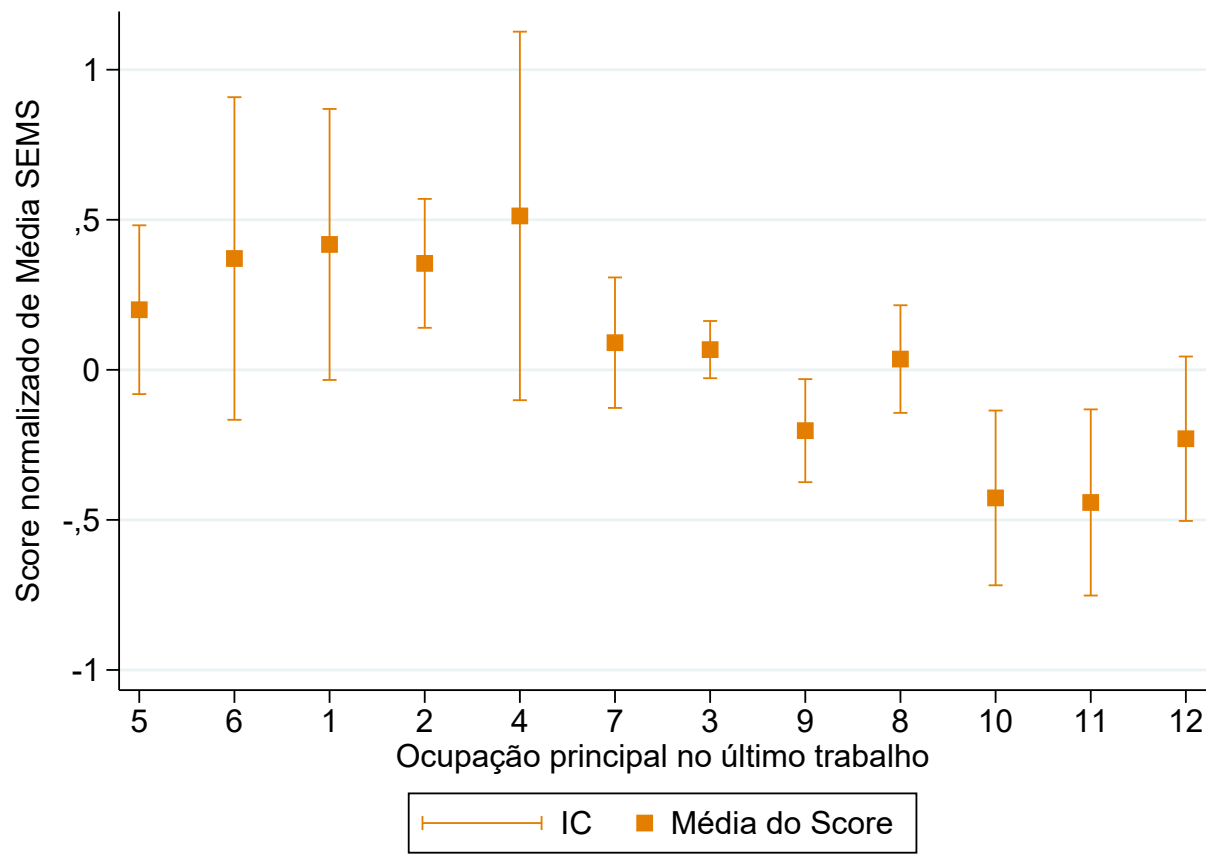

Notas:

1 - Função de direção, gerência.

2 - Função de coordenação, supervisão, técnico especialista, assessor ou equivalente, professor, médico, advogado.

3 - Função operacional, não especialista, assistente, operador ou equivalente.

4 - Empresário, grande proprietário rural, criador, industrial, empregador, investidor.

5 - Microempresário.

6 - Especialista, prestador de serviços de nível superior (advogado, médico, arquiteto, engenheiro, contador, dentista).

7 - Especialista, prestador de serviços de nível técnico (representante comercial, vendedor, mecânico, instalador, atleta).

8 - Conta própria em casa sem carteira (confecção, produção de alimentos, manicure ou equivalente).

9 - Conta própria fora de casa sem carteira (camelô, ambulante, biscate, bico, boia fria ou equivalente).

10 - Pequeno produtor rural, criador.

11 - Serviço doméstico com carteira assinada.

12 - Serviço doméstico sem carteira assinada.

Fonte: Inaf 2015. 
Figura 6 - Percentil socioemocional por decil salarial (Inaf 2015)

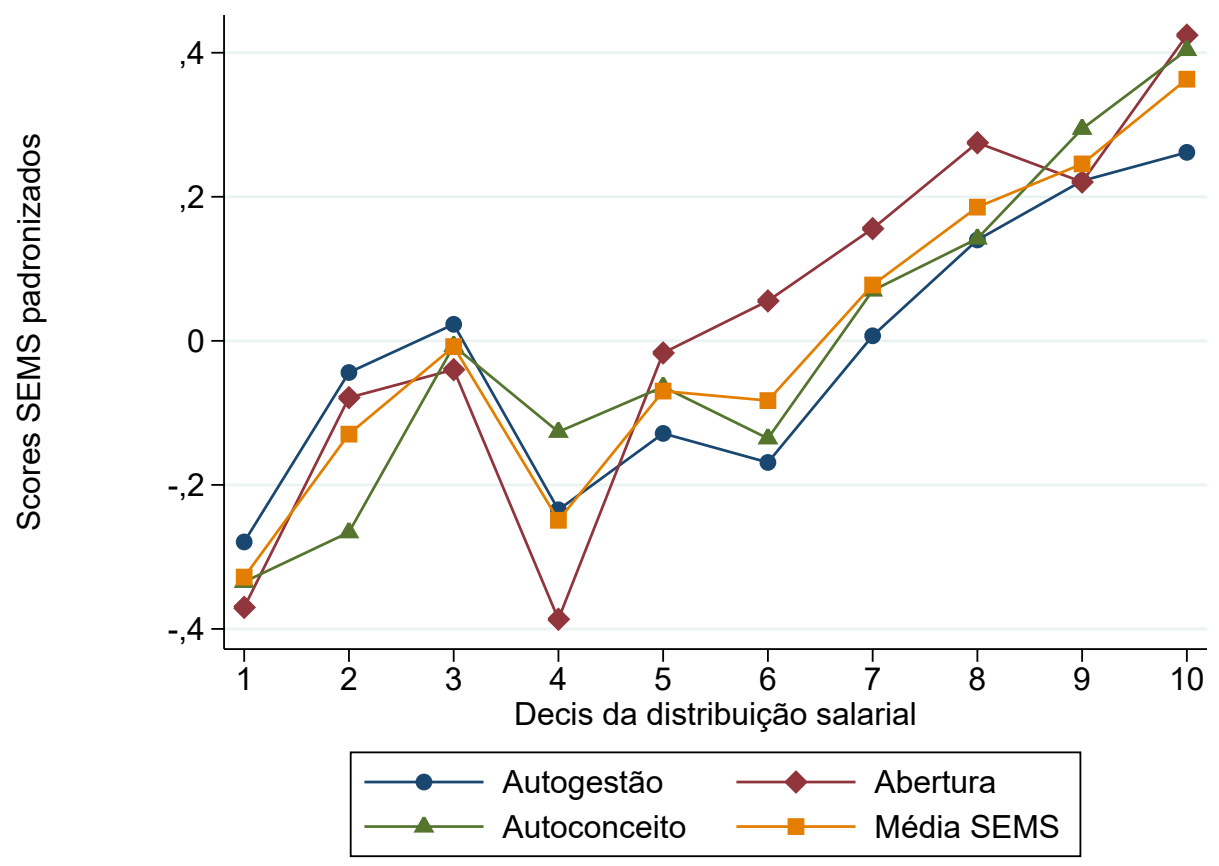

Fonte: Inaf 2015.

Figura 7 - Percentil socioemocional por decil salarial (Inaf 2015) - Autogestão

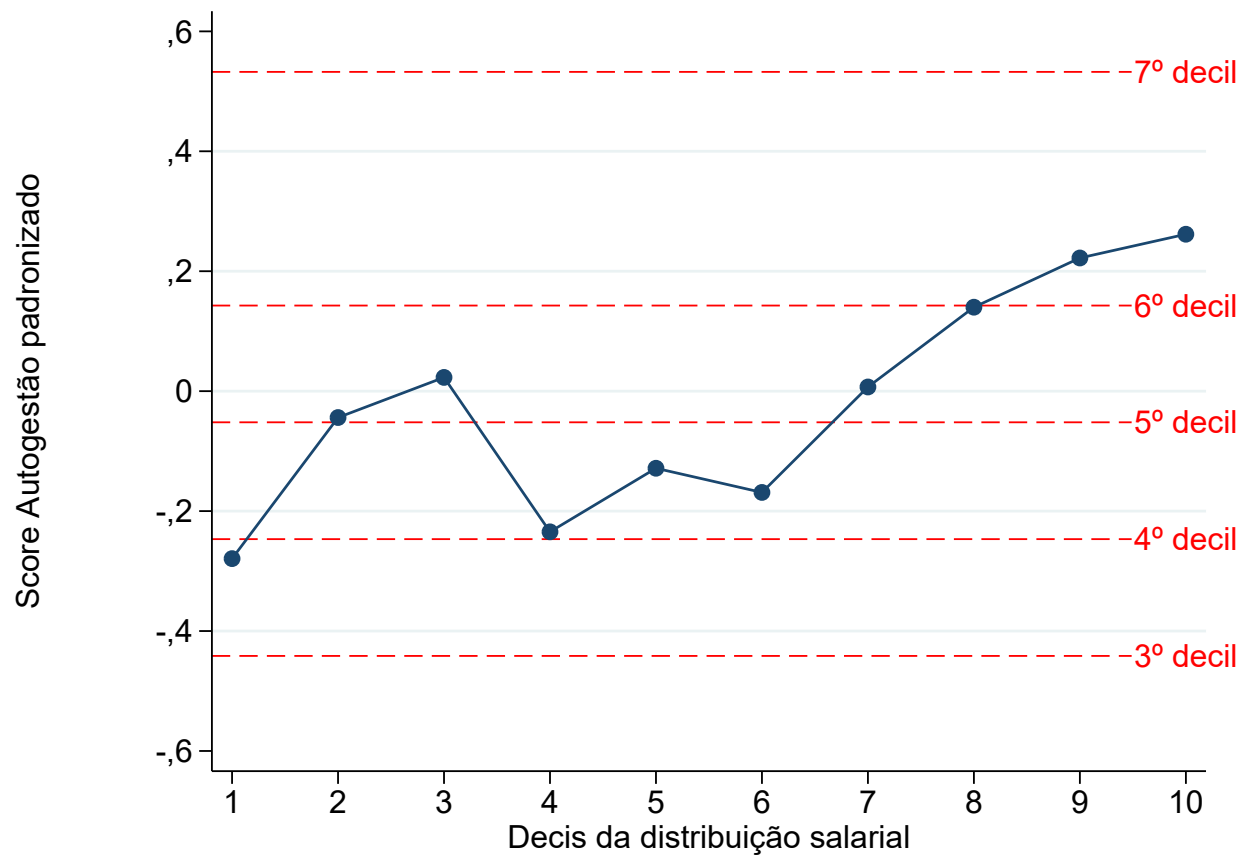

Fonte: Inaf 2015. 
Figura 8 - Percentil socioemocional por decil salarial (Inaf 2015) - Abertura ao Novo

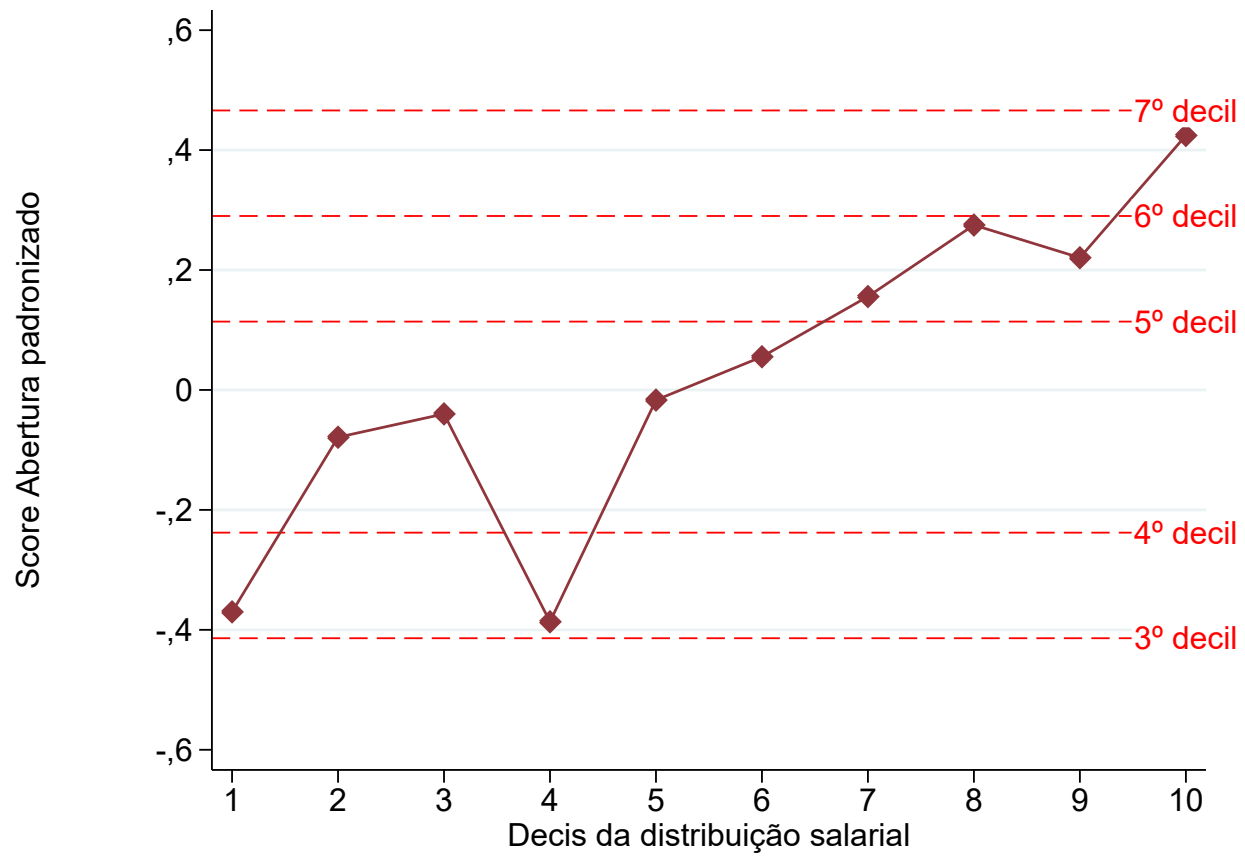

Fonte: Inaf 2015.

Figura 9 - Percentil socioemocional por decil salarial (Inaf 2015) - Autoconceito

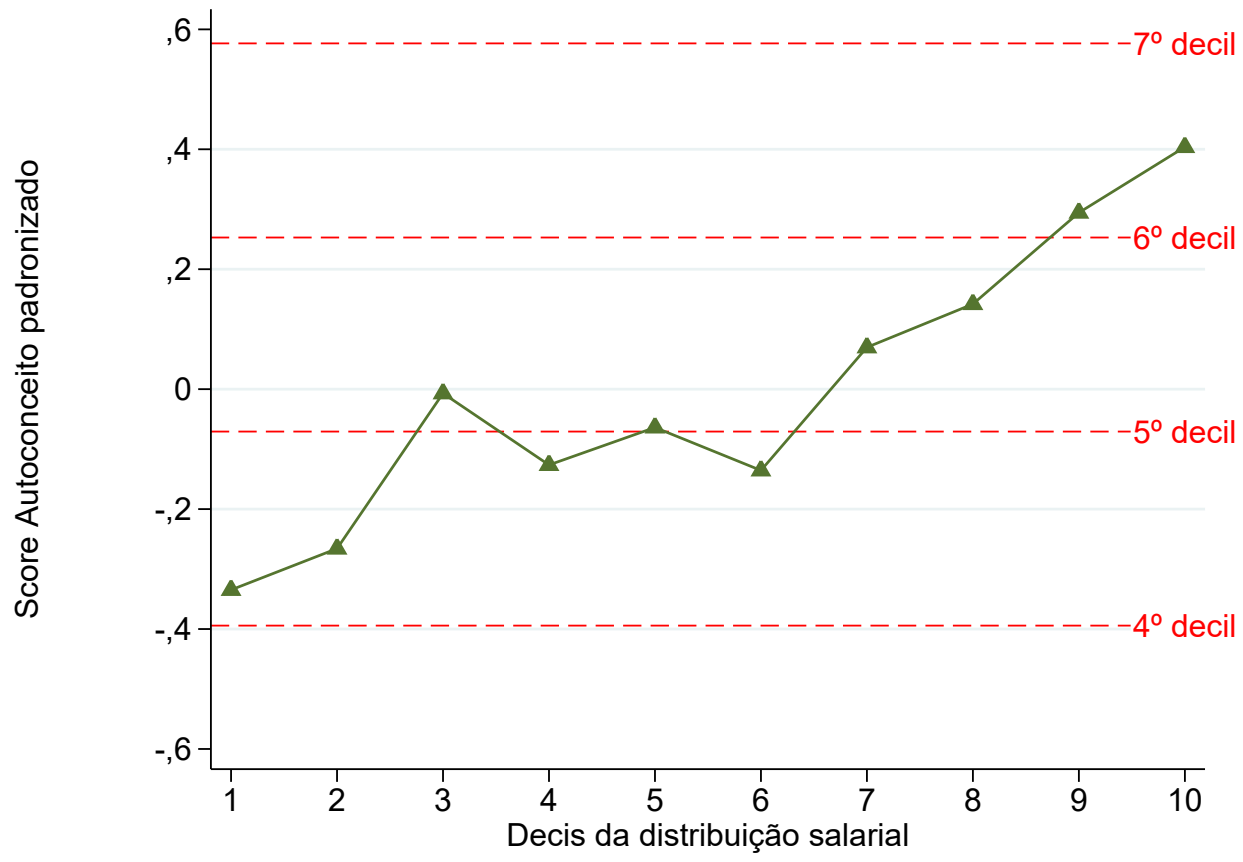

Fonte: Inaf 2015. 
Figura 10 - Percentil socioemocional por decil salarial (Inaf 2015) - Média SEMS

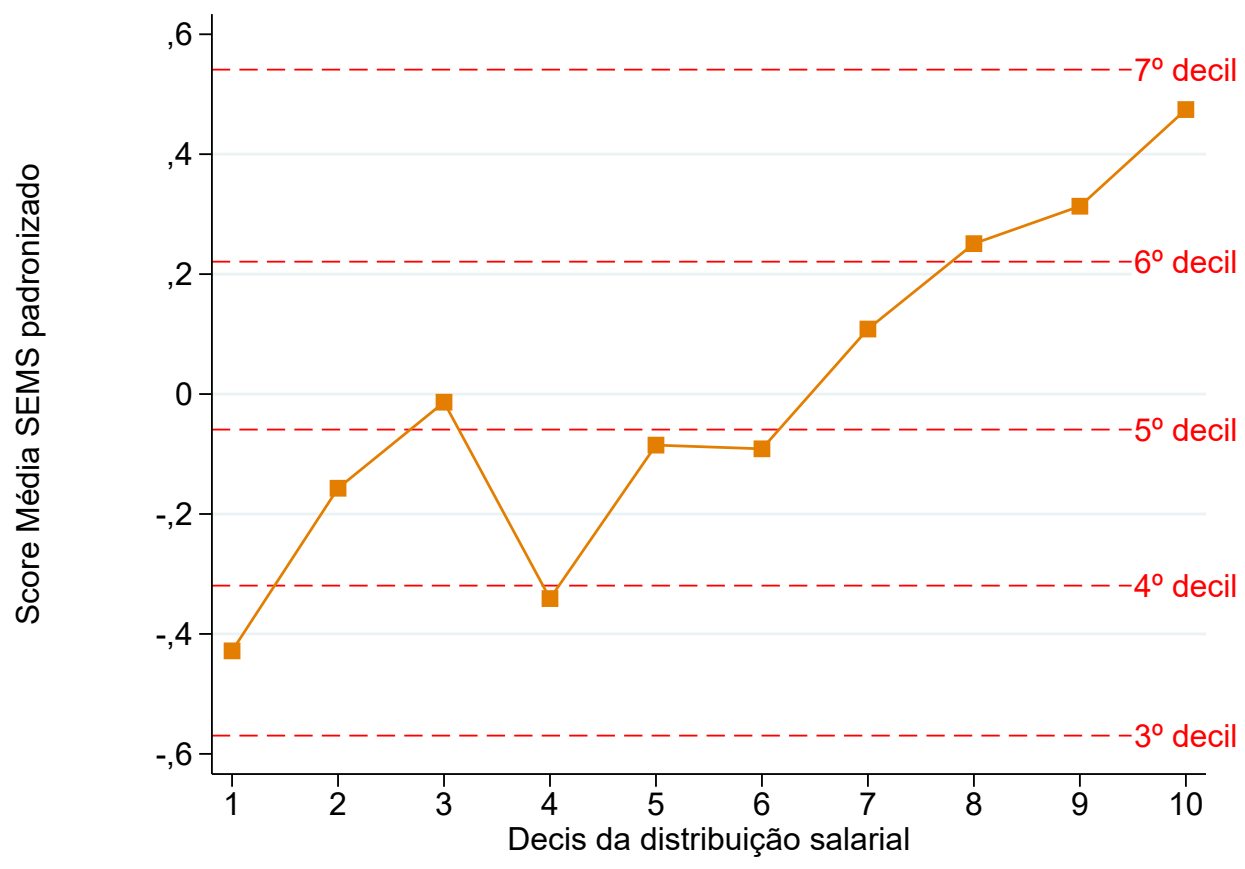

Fonte: Inaf 2015. 